\title{
Critical Assessment and Thermodynamic Modeling of the Fe-O-S System
}

\author{
Denis Shishin, Evgueni Jak, and Sergei A. Decterov
}

(Submitted December 23, 2014; in revised form February 13, 2015; published online March 13, 2015)

\begin{abstract}
The Fe-O-S system has been assessed over the whole composition range to produce a selfconsistent set of thermodynamic properties of all condensed phases from $298 \mathrm{~K}$ to above the liquidus temperatures at ambient pressure. The liquid phase from metallic liquid to sulfide melt to oxide melt is described by a single model developed within the framework of the quasichemical formalism. The model reflects the existence of strong short-range ordering in oxide, sulfide and oxysulfide liquid. Two ranges of maximum short-range ordering in the Fe-O system at approximately $\mathrm{FeO}$ and $\mathrm{Fe}_{2} \mathrm{O}_{3}$ compositions are taken into account. Parameters of thermodynamic models have been optimized to reproduce all available thermodynamic and phase equilibrium data. The thermodynamic modeling of the $\mathrm{Fe}-\mathrm{O}-\mathrm{S}$ system performed in the present study is of particular importance for the description of the solubility of oxygen in matte.
\end{abstract}

Keywords CALPHAD approach, critical assessment, liquidus, optimization, phase diagram, thermodynamic modeling, thermodynamic properties

\section{Introduction}

The present study is part of an ongoing research project which is aimed at developing a thermodynamic database for simulation of copper extraction from sulfide concentrates. The previous article dealt with the Cu-O-S system. ${ }^{[1]}$ The major phases that form during copper smelting and converting are: blister copper (a liquid metal phase rich in $\mathrm{Cu}$ ), matte (a molten sulfide phase containing mainly $\mathrm{Cu}, \mathrm{S}$ and $\mathrm{Fe}$ ), slag (a molten oxide phase) and gas. In principle, all three liquid phases represent just one liquid with miscibility gaps. Liquid metal, matte and slag can be completely miscible over certain ranges of temperature and composition, even though this normally does not happen under industrial conditions. It is desirable to have one general thermodynamic model which can describe all three liquid phases simultaneously, but this is very difficult to achieve because the model must reflect quite different atomic interactions that are intrinsic to metallic, sulfide and oxide phases.

Denis Shishin, Centre de Recherche en Calcul Thermochimique (CRCT), Deép. de Geénie Chimique, É cole Polytechnique, Montreal, QC, Canada; Evgueni Jak, PYROSERCH (Pyrometallurgy Research), School of Engineering, The University of Queensland, Brisbane, QLD, Australia; and Sergei A. Decterov, Centre de Recherche en Calcul Thermochimique (CRCT), Deép. de Geénie Chimique, Eé cole Polytechnique, Montreal, QC, Canada and PYROSERCH (Pyrometallurgy Research), School of Engineering, The University of Queensland, Brisbane, QLD, Australia.Contact e-mails: d.shishin@uq.edu.au,e.jak@uq.edu.au, and sergei.decterov@ polymtl.ca
As in the case of slags, mattes exhibit strong first-nearestneighbor (FNN) short-range ordering (SRO). Metal-sulfur pairs in matte are energetically favored over metal-metal and sulfur-sulfur pairs, but contrary to oxide melts, such as $\mathrm{CaO}-$ $\mathrm{SiO}_{2}$, where the ratio $\mathrm{O} /(\mathrm{Ca}+2 \mathrm{Si})$ is always very close to 1 , the composition of matte can substantially deviate from stoichiometric sulfides both towards metals and nonmetals. In the Fe-S system there is even no miscibility gap between liquid metal and liquid sulfide.

This study presents the thermodynamic modeling and optimization of model parameters for the Fe-O-S system, which complete "optimization" of all binary and ternary subsystems of the $\mathrm{Cu}-\mathrm{Fe}-\mathrm{O}-\mathrm{S}$ system using the Calphad technique. The results of the present study can be combined with the optimizations of the $\mathrm{Cu}-\mathrm{Fe}-\mathrm{S},{ }^{[2-4]} \mathrm{Cu}-\mathrm{O}-\mathrm{S},{ }^{[1]} \mathrm{Fe}-$ $\mathrm{O}^{[5]}$ and $\mathrm{Cu}-\mathrm{Fe}-\mathrm{O}^{[6]}$ systems to predict thermodynamic properties and phase equilibria in the $\mathrm{Cu}-\mathrm{Fe}-\mathrm{O}-\mathrm{S}$ quaternary system. Comparison of these predictions with the available experimental data will be reported elsewhere.

In the present study, all calculations were carried out using the FactSage thermochemical software and databases. ${ }^{[7]}$

\section{Thermodynamic Models}

The models for the liquid phase, monoxide, bcc and fcc solid solutions are discussed below. The models for spinel (magnetite) and pyrrhotite $\left(\mathrm{Fe}_{1-x} \mathrm{~S}\right)$ were reported earlier. ${ }^{[2,8]}$

\subsection{Liquid Solution}

No attempts were found in the literature to model the liquid phase in the Fe-O-S system over the entire composition range from liquid metal to oxysulfide melt. The thermodynamic model must describe drastic changes in the activities of sulfur and oxygen which are the result of strong SRO at the $\mathrm{FeS}$ and $\mathrm{FeO}$ compositions, respectively. Furthermore, in the Fe-O system, a second maximum in SRO is to be expected at the $\mathrm{Fe}_{2} \mathrm{O}_{3}$ composition, even 
though no experimental data are available in this region because of very high equilibrium oxygen pressures.

Thermodynamic modeling of the liquid phase and the available experimental data for the Fe-O and Fe-S systems were reviewed by Hidayat et al. $^{[5]}$ and Waldner and Pelton, ${ }^{[2]}$ respectively.

In the present study, a model for the liquid phase is developed within the framework of the quasichemical formalism. ${ }^{[9,10]}$ It has one sublattice containing four species: $\mathrm{Fe}^{\mathrm{II}}, \mathrm{Fe}^{\mathrm{III}}, \mathrm{S}$ and $\mathrm{O}$, where $\mathrm{Fe}^{\mathrm{II}}$ and $\mathrm{Fe}^{\mathrm{III}}$ correspond to two oxidation states of Fe. In the Fe-O system, the fraction of the $\mathrm{Fe}^{\mathrm{II}}-\mathrm{O}$ pairs goes through a maximum close to the $\mathrm{FeO}$ composition, while the Fe ${ }^{\text {III }}-\mathrm{O}$ pairs are most abundant at the $\mathrm{Fe}_{2} \mathrm{O}_{3}$ composition. All species are not charged, so the condition of electroneutrality is not imposed and the model is capable to represent the liquid phase from metal to nonmetals.

The formulae and notations of the quasichemical formalism have been described in detail elsewhere ${ }^{[9,10]}$ and only a brief summary is given here. To explain the meaning of parameters of the quasichemical formalism, let us consider a binary solution formed by components $\mathrm{A}$ and B. In the pair approximation of the modified quasichemical model, the following pair exchange reaction is considered:

$(\mathrm{A}-\mathrm{A})+(\mathrm{B}-\mathrm{B})=2(\mathrm{~A}-\mathrm{B}) ; \Delta g_{\mathrm{AB}}$

where $(i-j)$ represents a FNN pair and $\Delta g_{\mathrm{AB}}$ is the nonconfigurational Gibbs energy change for the formation of two moles of (A-B) pairs.

When the solution is formed from pure components $A$ and $\mathrm{B}$, some $(\mathrm{A}-\mathrm{A})$ and $(\mathrm{B}-\mathrm{B})$ pairs break to form $(\mathrm{A}-\mathrm{B})$ pairs, so the Gibbs energy of mixing is given by ${ }^{[9]}$ :

$\Delta G_{\text {mix }}=G-\left(n_{\mathrm{A}} g_{\mathrm{A}}^{\circ}+n_{\mathrm{B}} g_{\mathrm{B}}^{\circ}\right)=-T \Delta S^{\text {config }}+\left(\frac{n_{\mathrm{AB}}}{2}\right) \Delta g_{\mathrm{AB}}$

where $G$ is the Gibbs energy of the solution, $g_{\mathrm{A}}^{\circ}$ and $g_{\mathrm{B}}^{\circ}$ are the molar Gibbs energies of pure liquid components; $n_{\mathrm{A}}, n_{\mathrm{B}}$ and $n_{\mathrm{AB}}$ are the numbers of moles of $\mathrm{A}, \mathrm{B}$ and (A-B) pairs and $\Delta S^{\text {config }}$ is the configurational entropy given by randomly mixing the (A-A), $(\mathrm{B}-\mathrm{B})$ and $(\mathrm{A}-\mathrm{B})$ pairs. Since no exact expression is known for this entropy of mixing in three dimensions, an approximate equation is used which was shown ${ }^{[9]}$ to be an exact expression for a one dimensional lattice (Ising model) and to correctly reduce to the random mixing point approximation (Bragg Williams model) when $\Delta g_{\mathrm{AB}}$ is equal to zero.

$\Delta g_{\mathrm{AB}}$ can be expanded as an empirical polynomial in terms of the mole fractions of pairs ${ }^{[9]}$ :

$\Delta g_{\mathrm{AB}}=\Delta g_{\mathrm{AB}}^{\circ}+\sum_{(i+j) \geq 1} g_{\mathrm{AB}}^{i j} X_{\mathrm{AA}}^{i} X_{\mathrm{BB}}^{j}$

where $\Delta g_{\mathrm{AB}}^{\circ}$ and $g_{\mathrm{AB}}^{i j}$ are the parameters of the model which can be functions of temperature. In practice, only the parameters $g_{\mathrm{AB}}^{i 0}$ and $g_{\mathrm{AB}}^{0 j}$ need to be included.

The composition of maximum SRO is determined by the ratio of coordination numbers. Let $Z_{\mathrm{A}}$ and $Z_{\mathrm{B}}$ be the coordination numbers of $\mathrm{A}$ and $\mathrm{B}$. These coordination numbers can vary with composition as follows ${ }^{[9]}$ :
$\frac{1}{Z_{\mathrm{A}}}=\frac{1}{Z_{\mathrm{AA}}^{\mathrm{A}}}\left(\frac{2 n_{\mathrm{AA}}}{2 n_{\mathrm{AA}}+n_{\mathrm{AB}}}\right)+\frac{1}{Z_{\mathrm{AB}}^{\mathrm{A}}}\left(\frac{n_{\mathrm{AB}}}{2 n_{\mathrm{AA}}+n_{\mathrm{AB}}}\right)$

$\frac{1}{Z_{\mathrm{B}}}=\frac{1}{Z_{\mathrm{BB}}^{\mathrm{B}}}\left(\frac{2 n_{\mathrm{BB}}}{2 n_{\mathrm{BB}}+n_{\mathrm{AB}}}\right)+\frac{1}{Z_{\mathrm{BA}}^{\mathrm{B}}}\left(\frac{n_{\mathrm{AB}}}{2 n_{\mathrm{BB}}+n_{\mathrm{AB}}}\right)$

where $Z_{\mathrm{AA}}^{\mathrm{A}}$ and $Z_{\mathrm{AB}}^{\mathrm{A}}$ are the values of $Z_{\mathrm{A}}$ when all nearest neighbors of an $\mathrm{A}$ are As, and when all nearest neighbors of an $\mathrm{A}$ are $\mathrm{Bs}$, respectively, and where $Z_{\mathrm{BB}}^{\mathrm{B}}$ and $Z_{\mathrm{BA}}^{\mathrm{B}}$ are defined similarly. For example, in order to set the composition of maximum SRO at the molar ratio $n_{\mathrm{A}} / n_{\mathrm{B}}=2$, one can set the ratio $Z_{\mathrm{BA}}^{\mathrm{B}} / Z_{\mathrm{AB}}^{\mathrm{A}}=2$. Values of $Z_{\mathrm{BA}}^{\mathrm{B}}$ and $Z_{\mathrm{AB}}^{\mathrm{A}}$ are unique to the A-B binary system, while the value of $Z_{\mathrm{AA}}^{\mathrm{A}}$ is common to all systems containing $\mathrm{A}$ as a component.

Even though the model is sensitive to the ratio of the coordination numbers, it is less sensitive to their absolute values. We have found by experience that selecting values of the coordination numbers that are smaller than actual values often yields better results. This is due to the inaccuracy introduced by an approximate equation for the configurational entropy of mixing which is only exact for a one dimensional lattice. The smaller coordination numbers partially compensate this inaccuracy in the model equations, being more consistent with a one dimensional lattice. Therefore, the "coordination numbers" in our model are essentially treated as model parameters which are used mainly to set a physically reasonable composition of maximum SRO.

There are ten possible pairs formed by the species $\mathrm{Fe}^{\mathrm{II}}$, $\mathrm{Fe}^{\mathrm{III}}, \mathrm{O}$ and $\mathrm{S}$ in the Fe-O-S liquid phase. The fractions of all pairs are calculated by the Gibbs energy minimization procedure built into the FactSage software ${ }^{[7]}$ using the optimized model parameters. $\mathrm{Fe}^{\mathrm{II}}-\mathrm{Fe}^{\mathrm{II}}, \mathrm{O}-\mathrm{O}$ and $\mathrm{S}-\mathrm{S}$ are the predominant pairs at compositions close to pure $\mathrm{Fe}, \mathrm{O}$ and $\mathrm{S}$, respectively. The $\mathrm{Fe}^{\mathrm{II}}-\mathrm{O}, \mathrm{Fe}^{\mathrm{III}}-\mathrm{O}$ and $\mathrm{Fe}^{\mathrm{II}}-\mathrm{S}$ pairs are dominant in the oxide and sulfide liquids, whereas the fractions of the $\mathrm{Fe}^{\mathrm{II}}-\mathrm{Fe}^{\mathrm{III}}, \mathrm{Fe}^{\mathrm{III}}-\mathrm{Fe}^{\mathrm{III}}, \mathrm{O}-\mathrm{S}$ and $\mathrm{Fe}^{\mathrm{III}}-\mathrm{S}$ pairs are small at all compositions of interest.

"Coordination-equivalent" fractions $\left(Y_{\mathrm{m}}\right)$ are defined as

$Y_{\mathrm{m}}=Z_{\mathrm{m}} n_{\mathrm{m}} / \sum\left(Z_{i} n_{i}\right)$

In addition to the binary terms, the model can have ternary terms, $\Delta g_{\mathrm{AB}(\mathrm{C})}$, which give the effect of the presence of component $\mathrm{C}$ upon the energy $\Delta g_{\mathrm{AB}}$ of pair exchange reaction (1). Ternary terms are expanded as empirical polynomials either in terms of the mole fractions of pairs (with model parameters $g_{\mathrm{AB}(\mathrm{C})}^{i j k}$ ) or in terms of the "coordination-equivalent" fractions (with model parameters $q_{\mathrm{AB}(\mathrm{C})}^{i j k}$ ). In the quasichemical formalism, it is also possible to have Bragg Williams ternary terms, which are essentially the same as $q_{\mathrm{AB}(\mathrm{C})}^{i j k}$ terms, except for they are not taken into account in the calculation of the amounts of pairs.

Extrapolation of binary terms into the $\mathrm{Fe}^{\mathrm{II}}-\mathrm{Fe}^{\mathrm{III}}-\mathrm{O}-\mathrm{S}$ system is done by an asymmetric "Toop-like" method. ${ }^{[10]}$ The components are divided into two groups: metals ( $\mathrm{Fe}^{\mathrm{II}}$ 
and $\mathrm{Fe}^{\mathrm{III}}$ ) and nonmetals ( $\mathrm{S}$ and $\mathrm{O}$ ). By this means in every ternary subsystem, one component belongs to a different group than the other two. "Toop-like" extrapolation is applied, taking this "different" component as an asymmetric component. The formulae for ternary terms and for extrapolation of binary and ternary terms into a multicomponent system are discussed in detail elsewhere. ${ }^{[10]}$

\subsection{Solid FCC and BCC Iron}

Sulfur and oxygen are soluble to some extent in Fe metal, which has an fcc or bcc structure at the conditions of interest. The Bragg-Williams random mixing model was used for both phases with the following formula (per mole of atoms):

$$
\begin{aligned}
g= & \left(X_{\mathrm{Fe}} g_{\mathrm{Fe}}^{\mathrm{o}}+X_{\mathrm{O}} g_{\mathrm{O}}^{\mathrm{o}}+X_{\mathrm{S}} g_{\mathrm{S}}^{\mathrm{o}}\right)+R T\left(X_{\mathrm{Fe}} \ln X_{\mathrm{Fe}}\right. \\
& \left.+X_{\mathrm{O}} \ln X_{\mathrm{O}}+X_{\mathrm{S}} \ln X_{\mathrm{S}}\right)+ \\
& X_{\mathrm{Fe}} X_{\mathrm{S}} L_{\mathrm{Fe}, \mathrm{S}}+X_{\mathrm{Fe}} X_{\mathrm{O}} L_{\mathrm{Fe}, \mathrm{O}}
\end{aligned}
$$

where $X_{\mathrm{i}}$ and $g_{i}^{\circ}$ are the mole fraction and molar Gibbs energy of component $i, L_{i, j}$ represents the interaction energy between $i$ and $j$, which can be a function of temperature and composition.

\subsection{Monoxide (wüstite)}

Vogel and Fulling ${ }^{[11]}$ carried out equilibration and quenching experiments followed by analysis and reported that $\mathrm{FeO}$ and $\mathrm{FeS}$ are immiscible. Johto et al. ${ }^{[12]}$ also reported that sulfur was not soluble in wüstite based on equilibration/quenching/EMPA experiments. Hence, sulfur was assumed to be insoluble in monoxide.

The simplest polynomial model that was used for wüstite in the $\mathrm{Fe}-\mathrm{O}$ system $^{[5]}$ is accepted in the present study. It describes the nonstoichiometry of the wüstite phase towards oxygen using the Bragg-Williams approximation and assuming random mixing of $\mathrm{Fe}^{2+}$ and $\mathrm{Fe}^{3+}$ ions on cation sites. This assumption does not correspond to the real structure of wüstite, which is rather complex and not completely understood. However, it was shown in the assessment of the $\mathrm{Fe}-\mathrm{O}$ system ${ }^{[5]}$ that different models give almost identical representations of the entropy of wüstite as a function of composition, provided that the models adequately reproduce the absolute entropies of wüstite at several compositions and $25{ }^{\circ} \mathrm{C}$, which were obtained by the integration of the experimental low-temperature heat capacities.

The Gibbs energy per mole of components $\mathrm{FeO}$ and $\mathrm{FeO}_{1.5}$ is given by

$$
\begin{aligned}
g= & \left(X_{\mathrm{FeO}} g_{\mathrm{FeO}}^{\mathrm{o}}+X_{\mathrm{FeO}_{1.5}} g_{\mathrm{FeO}_{1.5}}^{\mathrm{o}}\right) \\
& +R T\left(X_{\mathrm{FeO}} \ln X_{\mathrm{FeO}}+X_{\mathrm{FeO}_{1.5}} \ln X_{\mathrm{FeO}_{1.5}}\right) \\
& +X_{\mathrm{FeO}} X_{\mathrm{FeO}_{1.5}} L_{\mathrm{FeO}, \mathrm{FeO}_{1.5}}
\end{aligned}
$$

where $g_{M}^{\mathrm{o}}$ and $X_{M}$ are the Gibbs energy and mole fraction of pure component $M$, respectively. The molar interaction energy $L_{M, N}$ between components $M$ and $N$ is expanded as a polynomial in the mole fractions of the components:
$L_{M, N}=\sum_{i, j \geq 0} q_{M, N}^{i j} X_{M}^{i} X_{N}^{j}$

where $q_{M, N}^{i j}$ are the binary model parameters.

\section{The Fe-S System}

The Fe-S system was optimized by Waldner and Pelton. ${ }^{[2]}$ The phase diagram is shown in Fig. 1. Comparisons with the experimental data, descriptions of thermodynamic models and optimized model parameters for all phases are given in Ref 2 . The description of the Fe-S liquid phase optimized by Waldner and Pelton ${ }^{[2]}$ was accepted in the present study with minor modifications. Contrary to the Fe-O liquid, the Fe-S liquid phase was modeled in such a way that Fe exists almost exclusively as $\mathrm{Fe}^{\mathrm{II}}$ over the whole composition range from metal to sulfur. This is because solid $\mathrm{Fe}_{2} \mathrm{~S}_{3}$ is not stable and there is no experimental evidence for strong SRO in the liquid phase at the $\mathrm{Fe}_{2} \mathrm{~S}_{3}$ composition which corresponds to very high $\mathrm{S}_{2}$ partial pressures.

A small modification of the $\Delta g_{\mathrm{Fe}^{\mathrm{II}} \mathrm{S}}^{\circ}$ parameter for the liquid phase was made in the present study to improve the description in the liquid iron region at $1500-1600{ }^{\circ} \mathrm{C}$. The resulted changes in the description of the system below $1500{ }^{\circ} \mathrm{C}$ are minimal compared to the original study of Waldner and Pelton. ${ }^{[2]}$ Even though some of the experimental data in the temperature range of $1600-1730{ }^{\circ} \mathrm{C}$ seem to be fitted not as good as by Waldner and Pelton, ${ }^{[2]}$ the region from 1500 to $1600{ }^{\circ} \mathrm{C}$ is more important for industrial applications and the experimental measurements are more accurate there. The differences are discussed in more detail elsewhere. ${ }^{[13]}$

\section{The Fe-O System}

The Fe-O system was reevaluated recently ${ }^{[5]}$ and the optimized phase diagram is shown in Fig. 2.

\section{The Fe-O-S System}

\subsection{Phase diagrams}

There are two ternary compounds in the Fe-O-S system, $\mathrm{FeSO}_{4}$ and $\mathrm{Fe}_{2}\left(\mathrm{SO}_{4}\right)_{3}$, which decompose forming the gas phase before melting at ambient pressure. Subsolidus reactions were studied by Skeaf and Espelund, ${ }^{[14]}$ Hsieh and Chang, ${ }^{[15]}$ Rosenqvist and Hofseth, ${ }^{16]}$ Musbah and Chang, ${ }^{[17]}$ Schaefer ${ }^{[18]}$ and Espelund and Jynge ${ }^{[19]}$ using the EMF technique in flowing $\mathrm{SO}_{2}$. Their data are summarized in Fig. 3. Most likely, these experiments do not correspond to equilibrium with the gas phase, which can contain other gaseous species such as $\mathrm{SO}_{3}, \mathrm{~S}_{2}$ and $\mathrm{O}_{2}$, but rather to a fixed potential of $\mathrm{SO}_{2}$, i.e. the other gaseous species do not form 


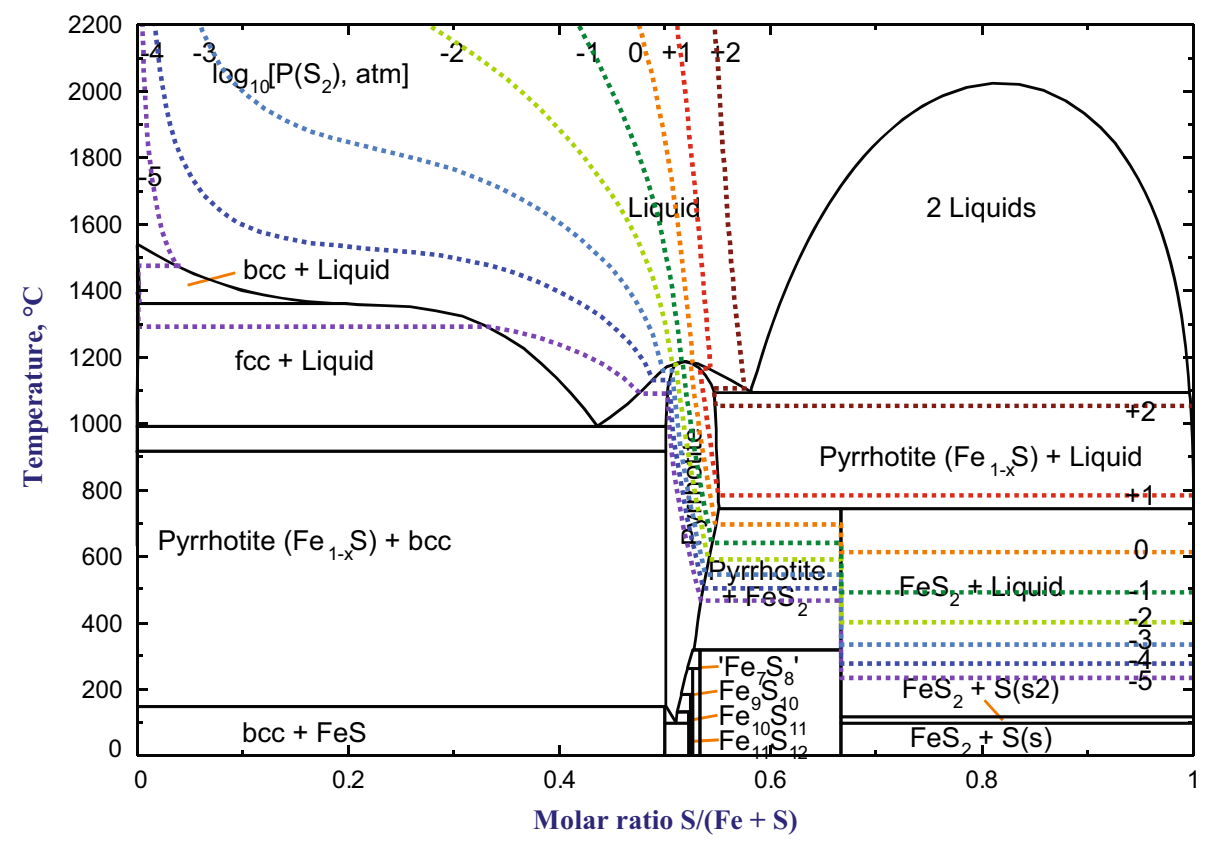

Fig. 1 Calculated phase diagram of the Fe-S system with superimposed $S_{2}$ isobars. Formation of the gas phase is suppressed

fast enough to significantly change the composition of flowing $\mathrm{SO}_{2}$. If the equilibrium with the gas phase were attained, it would be almost pure $\mathrm{SO}_{2}$ over the range of $P\left(\mathrm{O}_{2}\right)$ from $10^{-4}$ to $10^{-14} \mathrm{~atm}$. At higher oxygen potentials, amounts of $\mathrm{SO}_{3}$ and $\mathrm{O}_{2}$ become substantial, while at lower $P\left(\mathrm{O}_{2}\right)$ the partial pressure of $\mathrm{S}_{2}$ starts to increase. The composition of the gas flowing out of the furnace was not analyzed, but our calculations showed that large amounts of condensed phases in EMF cells would have to react in order to produce the gas phase of equilibrium composition, which is not what happened in the experiments.

Rosenqvist and Hynne ${ }^{[20]}$ carried out equilibration, quenching and analysis experiments and reported that $\mathrm{FeS}$ does not dissolve in $\mathrm{Fe}_{3} \mathrm{O}_{4}$ spinel.

Liquid that appears in the system expands from molten nonstoichiometric FeS towards FeO. At high temperatures it also spreads to liquid metal. The evaluated phase diagram of the $\mathrm{Fe}-\mathrm{O}-\mathrm{S}$ system at $1200{ }^{\circ} \mathrm{C}$ and at the total pressure of $1 \mathrm{~atm}$ is shown in Fig. 4.

Phase equilibria in the Fe-S-O system were studied repeatedly. ${ }^{[11,12,21-29]}$

Naldrett ${ }^{[25]}$ determined the iron-wüstite-troilite-liquid (Fe"FeO"-"FeS"-L) ternary eutectic temperature by melting pyrrhotite, wüstite and iron in silica, iron or silver crucibles. Experiments in silica and iron crucibles gave $915 \pm 2{ }^{\circ} \mathrm{C}$, while in silver crucibles the eutectic temperature was measured to be $905 \pm 2{ }^{\circ} \mathrm{C}$. The composition of this eutectic was determined by melting in silver crucibles and is shown in Fig. 5. Even though the eutectic temperature obtained in silver crucibles was lower, the author claimed that the presence of Ag had only a small effect on the Fe:S:O ratio in the liquid phase at the eutectic temperature. Naldrett ${ }^{[25]}$ also reported the temperature and composition of the magnetite- wüstite-troilite-liquid (" $\mathrm{Fe}_{3} \mathrm{O}_{4}$ "-"“FeO"-“"FeS"-L) ternary peritectic. The experiments were conducted in evacuated and sealed silica tubes, hence it was possible to study melts with high equilibrium vapor pressures without affecting the composition. The results obtained in contact with silica tubes should probably be interpreted as corresponding to the $\mathrm{Fe}-\mathrm{O}-$ $\mathrm{S}-\mathrm{Si}$ system at $\mathrm{SiO}_{2}$ saturation. Naldrett suggested that since the presence of $\mathrm{SiO}_{2}$ did not affect much the temperature of the $\mathrm{Fe}-$ "FeO"-"FeS"-L eutectic, it should not have a strong effect on the " $\mathrm{Fe}_{3} \mathrm{O}_{4}$ "-" $\mathrm{FeO}$ "-" $\mathrm{FeS}$ "-L invariant temperature and composition. The temperature was found to be $934 \pm 2{ }^{\circ} \mathrm{C}$ and the composition is shown in Fig. 5 .

The experiments of Hilty and Crafts ${ }^{[21]}$ involved melting mixtures of $\mathrm{FeS}$ and $\mathrm{Fe}_{2} \mathrm{O}_{3}$ in iron crucibles. The melting was carried out in Ar, assuming that the $\mathrm{O}: \mathrm{S}$ ratio in the samples did not change significantly due to low $P\left(\mathrm{SO}_{2}\right)$ and $P\left(\mathrm{~S}_{2}\right)$ in the iron-saturated system. Taking into account the fluctuations of cool Ar flow, the accuracy in temperature determination suggested by the authors was $\pm 10^{\circ} \mathrm{C}$. Preliminary studies were conducted to prove that the reaction time of $2 \mathrm{~h}$ was sufficient for equilibration. After equilibration, samples were quenched in water and studied by chemical analysis and microscopic examination. The results are plotted in Fig. 5 and 6(a-f).

Darken and Gurry (cited in Ref 22) melted the charge of pyrrhotite and wüstite. The composition of pyrrhotite corresponded to $\mathrm{FeS}_{0.942}$ and that of wüstite - to $\mathrm{FeO}_{1.054}$. Samples were placed in iron crucibles in an atmosphere of purified $\mathrm{N}_{2}$ and annealed at controlled temperature. No special precautions were made in order to keep the samples on the $\mathrm{FeS}_{0.942}-\mathrm{FeO}_{1.054}$ section, so the initial compositions could have changed due to dissolution of iron from the crucibles or evaporation of oxygen and sulfur into the gas 


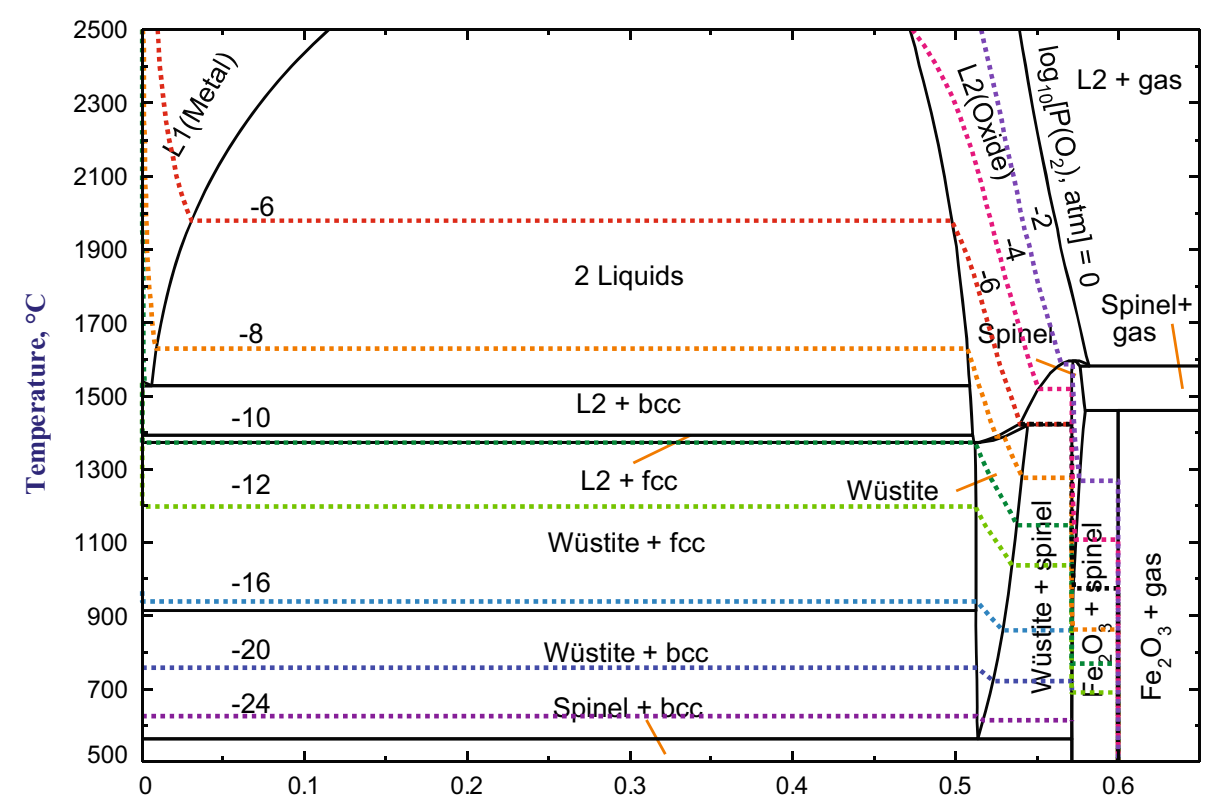

(a)

Molar ratio $\mathrm{O} /(\mathrm{Fe}+\mathrm{O})$

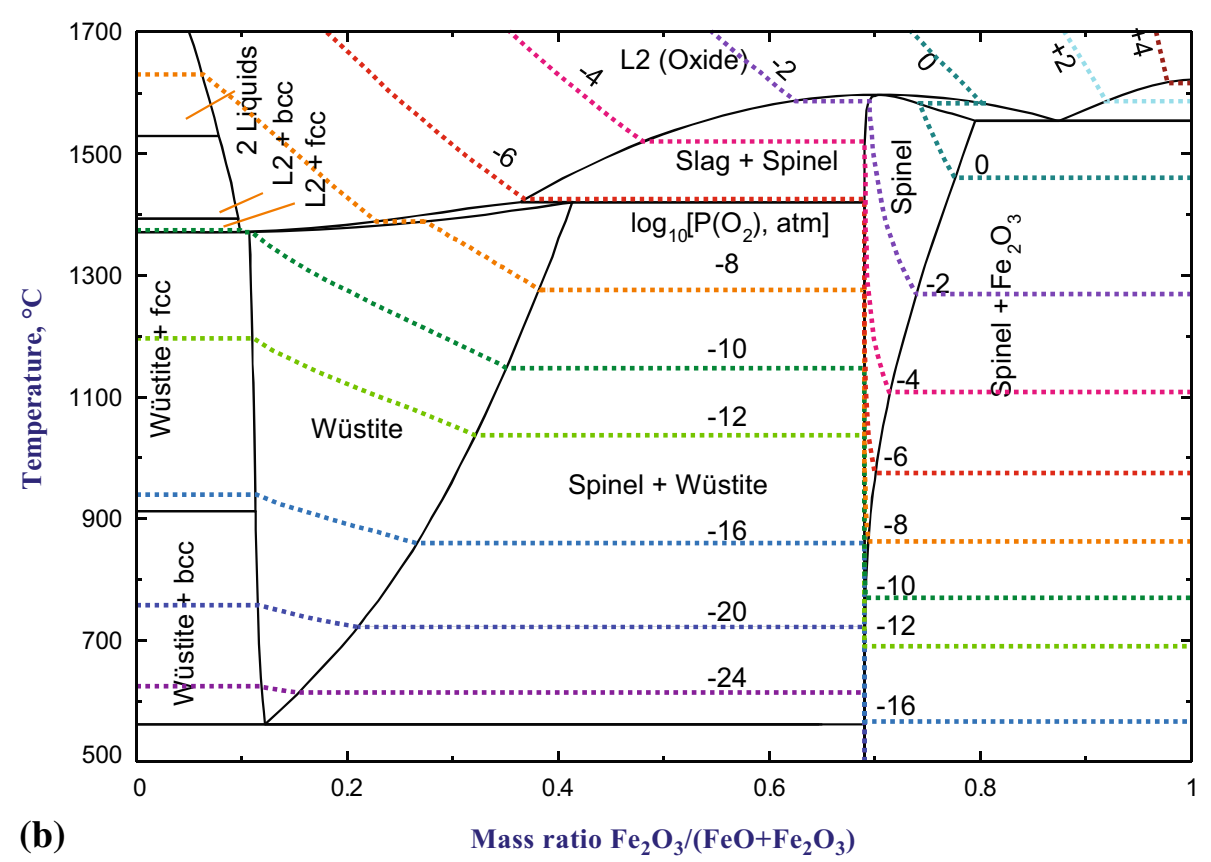

Fig. 2 (a) Optimized phase diagram of the Fe-O system. ${ }^{[5]}$ The dashed lines are calculated oxygen isobars. The gas phase is suppressed. (b) Enlarged $\mathrm{FeO}-\mathrm{Fe}_{2} \mathrm{O}_{3}$ part of the same diagram

phase. The phase boundaries corresponding to precipitation of the pyrrhotite and wüstite phases were obtained by microscopic examination of samples quenched into mercury. The structural characteristics of the polished samples made it possible to determine whether quenching was made from the temperatures above or below these phase boundaries. The compositions of the liquid phase were not measured, which increases the uncertainty of the determined phase boundaries. These experimental points are plotted in Fig. 7, assuming that the samples were in equilibrium with iron and that the $\mathrm{O}: \mathrm{S}$ ratio in the samples did not change during the experiments.

Vogel and Fulling ${ }^{[11]}$ used corundum crucibles to melt mixtures of $\mathrm{Fe}, \mathrm{Fe}_{2} \mathrm{O}_{3}$ and $\mathrm{S}$ in Ar. Quenched samples were examined microscopically. The temperature of $920{ }^{\circ} \mathrm{C}$ was measured for the $\mathrm{Fe}-" \mathrm{FeS} "$ "“FeO"-L eutec- 


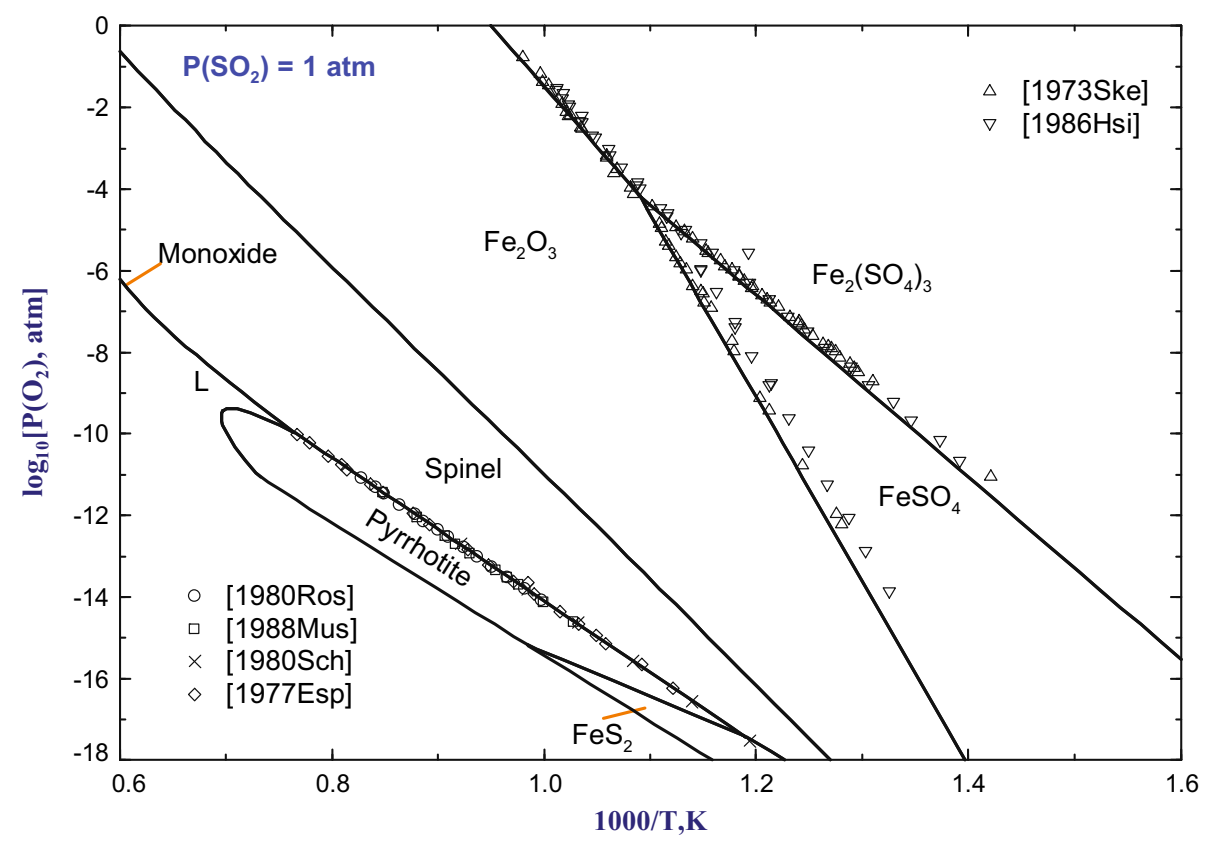

Fig. 3 Potential phase diagram of the Fe-O-S system at $P\left(\mathrm{SO}_{2}\right)=1 \mathrm{~atm}$

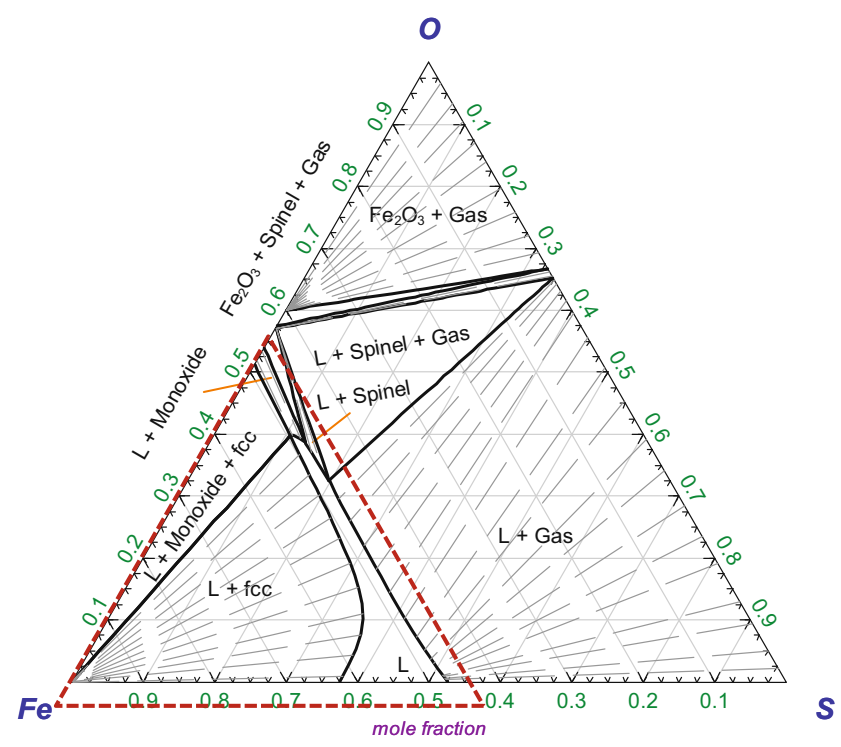

Fig. 4 Calculated isothermal section of the Fe-O-S phase diagram at $1200{ }^{\circ} \mathrm{C}$ and $P=1 \mathrm{~atm}$

tic. The composition of this eutectic is shown in Fig. 5. The authors also reported the "FeO-FeS" section of the $\mathrm{Fe}-\mathrm{O}-\mathrm{S}$ phase diagram, but it remains unclear how much the actual compositions of their samples deviated from this section. As can be seen from Fig. 5, iron must have precipitated from the initial compositions along most of the FeO-FeS section to produce oxysulfide liquid in equilibrium with monoxide (wüstite). Hence, the monoxide liquidus reported by Vogel and Fulling ${ }^{[11]}$ can be compared with the calculated phase diagram in equilibrium with iron shown in Fig. 7.

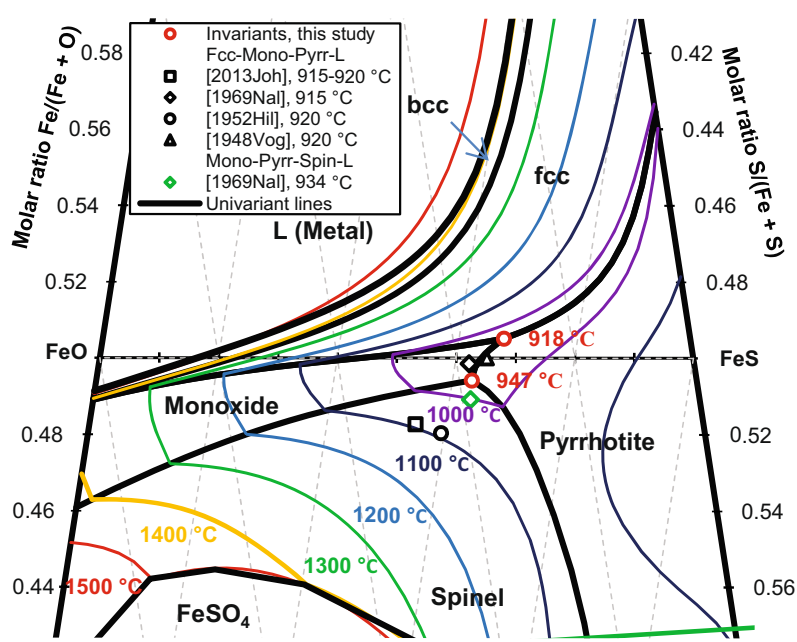

Fig. 5 Liquidus projection of the Fe-O-S system (FeO-FeS region). Formation of the gas phase is suppressed. Points show the compositions of invariant points reported in studies ${ }^{[11,12,21,25]}$

Yazawa and Kameda ${ }^{[28]}$ presented the $\mathrm{Cu}_{2} \mathrm{~S}-\mathrm{FeO}-\mathrm{FeS}$ phase diagram at iron saturation. The extrapolation of their liquidus to the FeO-FeS section is given in Fig. 7.

Rosenqvist and Hartvig ${ }^{[23]}$ equilibrated oxysulfide liquid with magnetite and the $\mathrm{SO}_{2}-\mathrm{S}_{2}$ gas flow with controlled $P\left(\mathrm{~S}_{2}\right)$ at a total pressure of $1 \mathrm{~atm}$ and 1135 or $1185^{\circ} \mathrm{C}$. Crucibles were made from alumina lined with magnetite. The liquid phase was analyzed for $\mathrm{Fe}, \mathrm{S}$ and $\mathrm{O}$ by conventional methods: precipitation of iron as $\mathrm{Fe}_{2} \mathrm{O}_{3}$, electro-deposition of $\mathrm{S}$ as $\mathrm{BaSO}_{4}$ and determination of the oxygen content by the hydrogen-reduction method (heating the sample in hydrogen to convert oxygen into water, which 


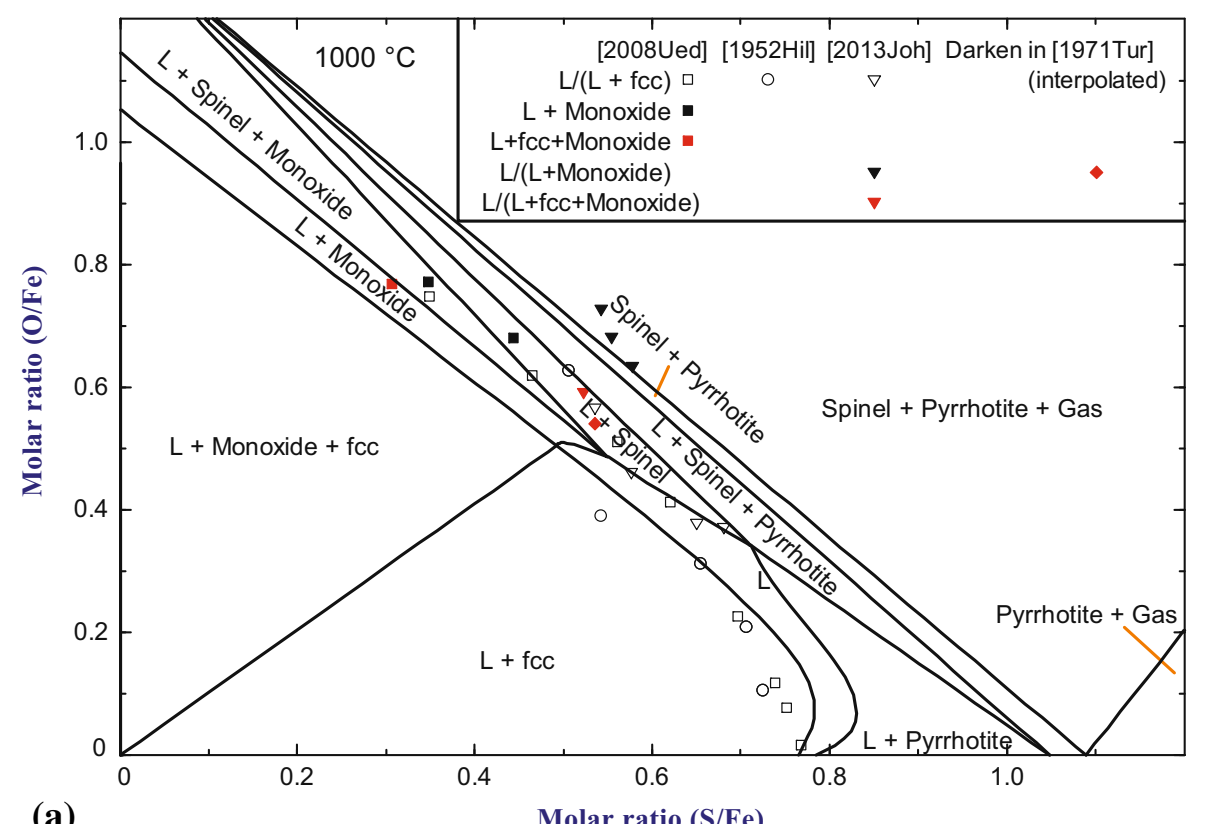

(a)

Molar ratio (S/Fe)

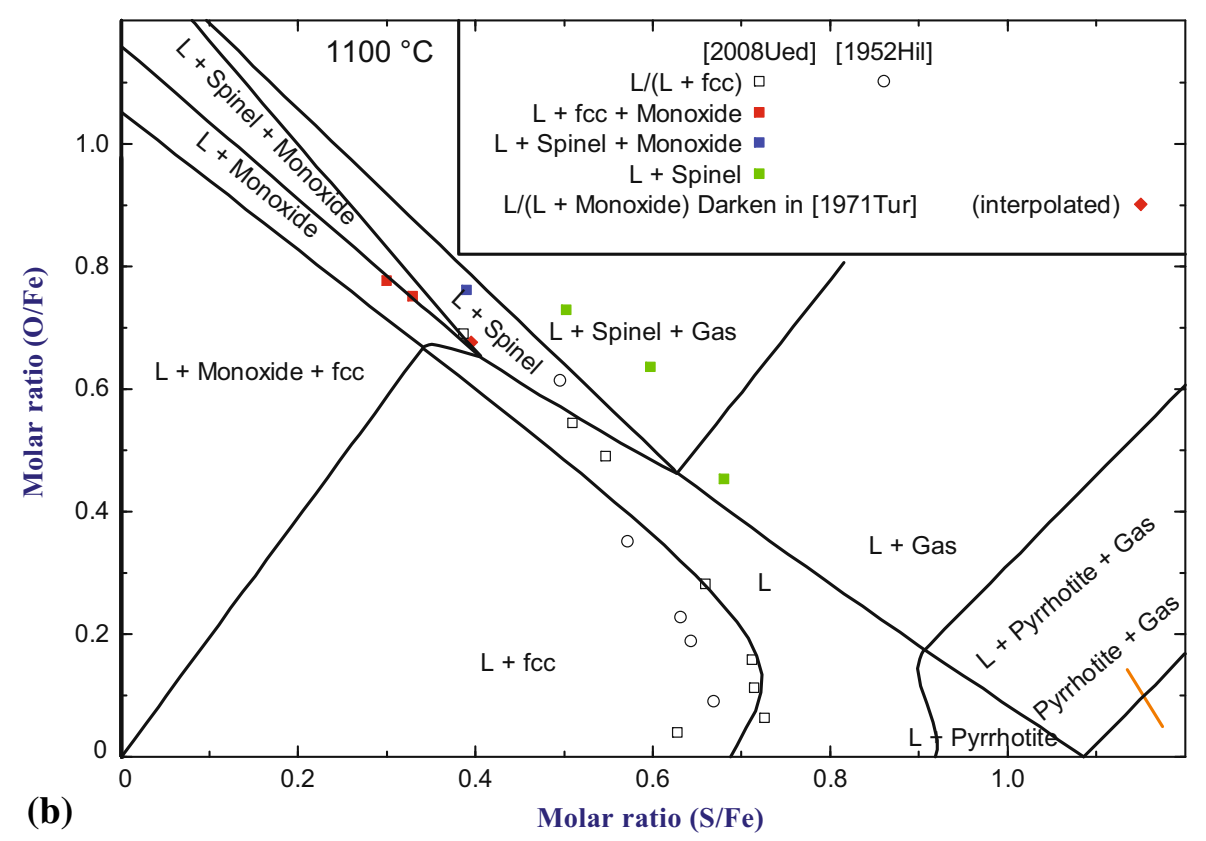

Fig. 6 Isothermal sections of the Fe-S-O phase diagram with superimposed $\mathrm{O}_{2}$ and $\mathrm{S}_{2}$ isobars at the total pressure of 1 atm and (a) $1000{ }^{\circ} \mathrm{C}$, (b) $1100{ }^{\circ} \mathrm{C}$, (c) $1120{ }^{\circ} \mathrm{C}$, (d) $1200{ }^{\circ} \mathrm{C}$, (e) $1300{ }^{\circ} \mathrm{C}$, (f) $1400{ }^{\circ} \mathrm{C}$ and (g) $1450{ }^{\circ} \mathrm{C}$. Experimental points are from Ref $21-24$, 26, and 27. The solid lines are the calculated phase boundaries. The dotted and dashed lines in figures (c to e) are the calculated $\mathrm{O}_{2}$ and $\mathrm{S}_{2}$ isobars, respectively. The experimental tie-lines in figures ( $\mathrm{f}$ and $\mathrm{g}$ ) are shown by the dotted lines

was absorbed with $\mathrm{P}_{2} \mathrm{O}_{5}$ ). The compositions of the liquid phase in equilibrium with magnetite and $\mathrm{SO}_{2}-\mathrm{S}_{2}$ gas are plotted in Fig. 6(c,d).

Bog and Rosenqvist ${ }^{[24]}$ prepared the $\mathrm{H}_{2} \mathrm{~S}-\mathrm{H}_{2} \mathrm{O}-\mathrm{H}_{2}$ gas mixtures of certain composition and equilibrated them with iron sulfide at $1120^{\circ} \mathrm{C}$, i.e. both $P\left(\mathrm{O}_{2}\right)$ and $P\left(\mathrm{~S}_{2}\right)$ were fixed in these experiments. The crucible material was not reported. The composition of resulting melt was determined by unspecified chemical methods. Some experiments were conducted at iron saturation. The compositions of the samples in equilibrium with iron along with oxygen and sulfur isobars are plotted in Fig. 6(c).

Ueda et al. ${ }^{[27]}$ melted mixtures of $\mathrm{Fe}, \mathrm{Fe}_{2} \mathrm{O}_{3}$ and $\mathrm{FeS}$ in iron crucibles at $1000-1400{ }^{\circ} \mathrm{C}$. The oxygen partial pressure was measured using the following oxygen concentration cell:

$\mathrm{Pt}|\mathrm{Ni}, \mathrm{NiO}| \mathrm{ZrO}_{2}(\mathrm{CaO}) \mid$ specimen $|\mathrm{Re}| \mathrm{Pt}$

(Eq 10) 

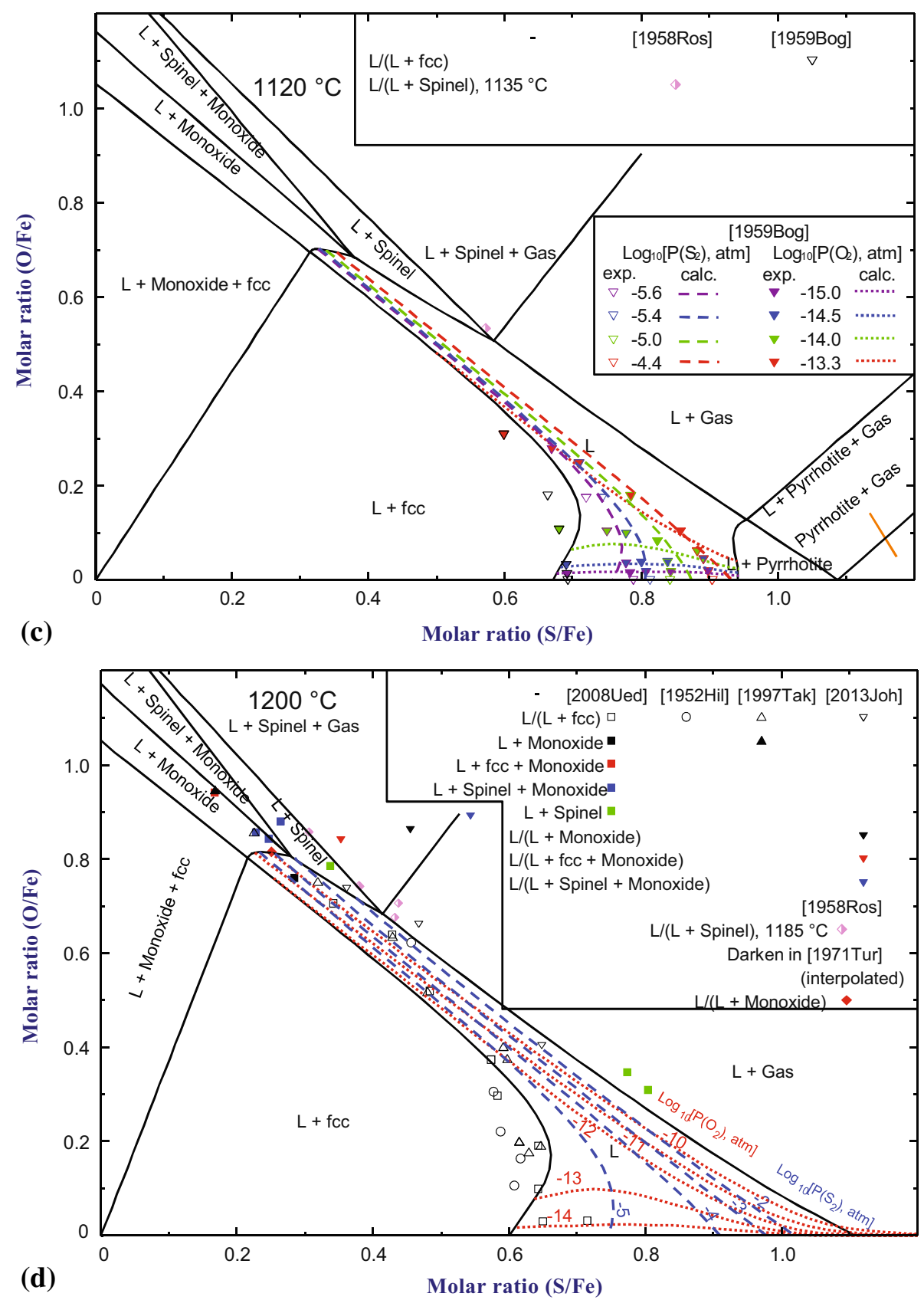

Fig. 6 continued

After equilibration, the crucible was quenched in a water bath. Compositions of the specimens were determined by chemical analysis. Oxygen and sulfur contents were determined by reduction with hydrogen. Iron was determined by titration methods and from the mass balance. The phase equilibrium results are shown in Fig. $6(\mathrm{a}, \mathrm{b}, \mathrm{d}, \mathrm{e}, \mathrm{f})$ and the oxygen potential measurements are given in the next Section in Fig. 8 and 9.

Takeda ${ }^{[26]}$ melted the Fe-S-O mixtures in iron crucibles at 1200 and $1300{ }^{\circ} \mathrm{C}$ and measured the oxygen potential with a sensor similar to cell (10). The method used for chemical analysis was not reported. The results are shown in Fig. 6(d,e) and in the next Section in Fig. 9.

Johto et al. ${ }^{[12]}$ heated mixtures of the pure Fe, FeS and $\mathrm{Fe}_{2} \mathrm{O}_{3}$ powders in crucibles lined with iron foil. The experiments were conducted either in an $\mathrm{Ar}$ atmosphere or at $P\left(\mathrm{O}_{2}\right)$ controlled by the $\mathrm{CO} / \mathrm{CO}_{2}$ gas flow. After heat treatment, the samples were quenched. Microscopic observations showed that the Fe-"FeS"-"FeO"-L eutectic should be between 915 and $920{ }^{\circ} \mathrm{C}$. The iron and sulfur contents of 

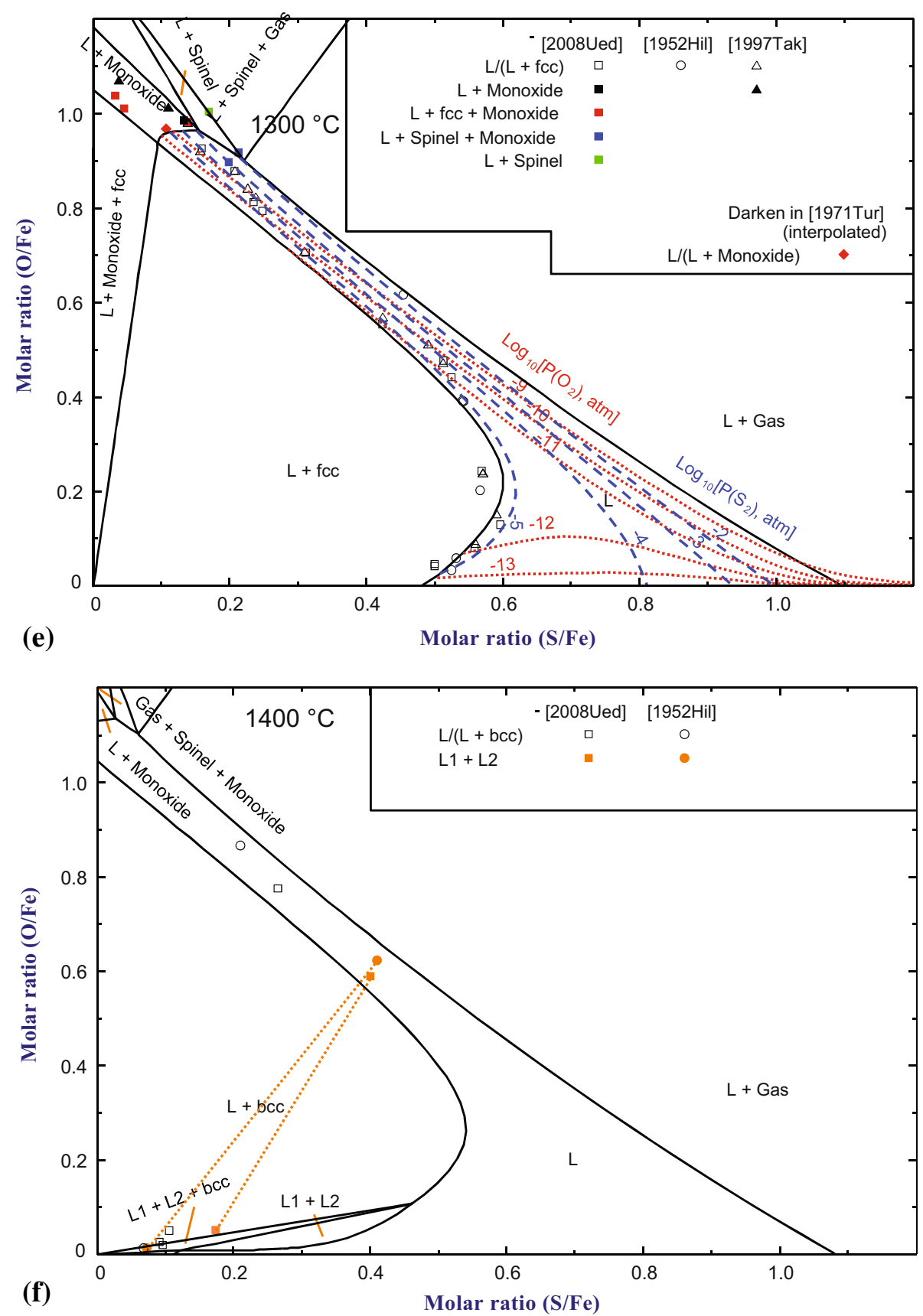

Fig. 6 continued

the liquid phase in equilibrium with solid phases were determined by EMPA analysis. The oxygen content was not measured directly and was obtained by difference, which makes the reported compositions relatively less accurate. The position of the eutectic point suggested by Johto et al. ${ }^{[12]}$ is shown in Fig. 5 and 7. The compositions of the liquid phase in equilibrium with solids are plotted in Fig. 6(a, d). The dependence of the liquid composition on $P\left(\mathrm{O}_{2}\right)$ is discussed in the next Section and plotted in Fig. 9.

Lee et al. ${ }^{[29]}$ equilibrated mixtures of "FeO", $\mathrm{FeS}$ and $\mathrm{Ag}$ in iron crucibles under the flow of $\mathrm{CO} / \mathrm{CO}_{2}$. After equilibration, silver was analyzed for sulfur and "each component" of oxysulfide liquid was determined "by a gas analyzer and titration method". Since the results of analyses are not provided, it is not possible to evaluate the extent of contamination of the oxysulfide phase by silver. The measured compositions of oxysulfide liquid in equilibrium with iron were plotted by Lee et al. ${ }^{[29]}$ in the Fe-S-O triangle. These compositions have much higher sulfur content than reported by Hilty and Crafts, ${ }^{[21]}$ Ueda et al., ${ }^{[27]}$ Takeda $^{[26]}$ and even Johto et al., ${ }^{[12]}$ which may be due to the presence of silver in the liquid phase. Hence, 


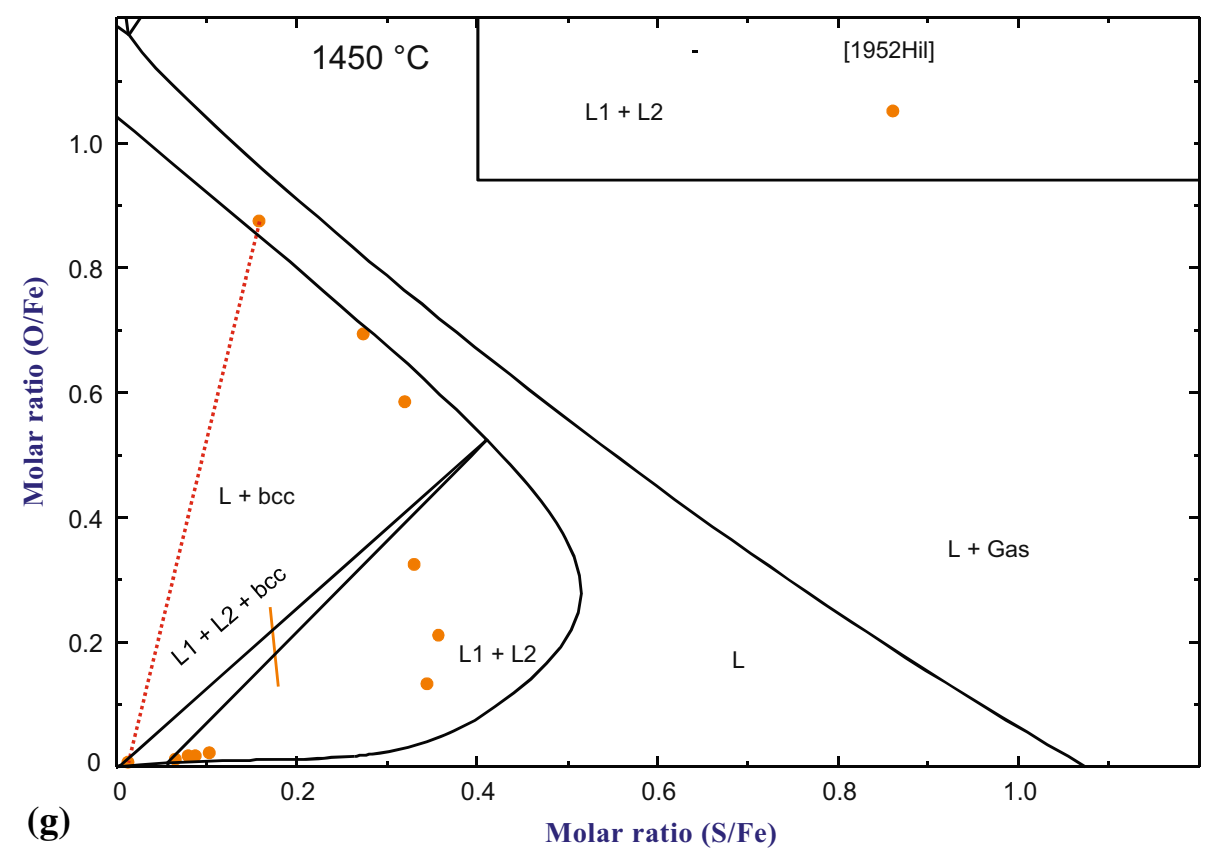

Fig. 6 continued

the results of Lee et al. ${ }^{[29]}$ were not used in the present optimization.

As can be seen from Fig. 5 and 6, the phase relations in the Fe-S-O system are complex and somewhat unusual. The liquid phase substantially deviates from the $\mathrm{FeO}-\mathrm{FeS}$ join both towards iron and nonmetals. It splits into two liquids at high temperatures. The miscibility gap becomes wider rather than narrower with an increase in temperature. The measured compositions are not very accurate, which is evident from the wide scatter of the experimental points corresponding to the $\mathrm{L} /(\mathrm{L}+\mathrm{fcc})$ phase boundary shown in Fig. 6. The reported FeO-FeS phase diagram ${ }^{[11,22,28]}$ was measured at iron saturation rather than by studying the compositions along the $\mathrm{FeO}-\mathrm{FeS}$ section, which inevitably shifts the composition of the liquid phase from the FeO-FeS join (see Fig. 5). The calculated phase diagram at iron saturation is shown in Fig. 7.

\subsection{Solubility of Oxygen and Sulfur in Oxysulfide Liquid}

The solubility of oxygen and sulfur in oxysulfide liquid was measured by Bog and Rosenqvist, ${ }^{[24]}$ Dewing and Richardson, ${ }^{[30]}$ Nagamori and Kameda, ${ }^{[31]}$ Kameda and Yazawa, ${ }^{[32]}$ Stofko et al., ${ }^{[33]}$ Mintsis et al., ${ }^{[34]}$ Blatov et al., ${ }^{[35]}$ Nagamori and Yazawa, ${ }^{[36]}$ Rose and Brenan, ${ }^{[37]}$ Fonseca et al., ${ }^{[38]}$ Ueda et al. ${ }^{[27]}$ and Johto and Henao. ${ }^{[12]}$

Dewing and Richardson ${ }^{[30]}$ heated small samples of the condensed phase in a stream of $\mathrm{N}_{2}-\mathrm{S}_{2}-\mathrm{SO}_{2}$. The melts were held in a platinum spiral. After attaining equilibrium, the samples were quenched and analyzed by treatment in hydrogen. The resulting $\mathrm{H}_{2} \mathrm{~S}$ was absorbed by the zinc acetate solution. Residual metal was dissolved in acid giving the iron content. Insoluble platinum was weighted. It was found that the quenched samples contained up to $2 \mathrm{~mol} \%$ of platinum sulfide at high $P\left(\mathrm{~S}_{2}\right)$. Thus, iron, sulfur and platinum were determined directly and oxygen by difference. Most data points were obtained at $1206{ }^{\circ} \mathrm{C}$. The partial pressures of $\mathrm{S}_{2}$ and $\mathrm{SO}_{2}$ were reported by the authors and equilibrium $P\left(\mathrm{O}_{2}\right)$ was calculated in this study. The data are plotted in Fig. 8 .

Nagamori and Kameda ${ }^{[31]}$ equilibrated Fe-O-S melts with CO- $\mathrm{CO}_{2}-\mathrm{SO}_{2}$ gas mixtures at $1200{ }^{\circ} \mathrm{C}$ in alumina crucibles. The quenched samples were analyzed for the iron content by titration with $\mathrm{KMnO}_{4}$, for sulfur by precipitation as $\mathrm{BaSO}_{4}$, and for oxygen by the hydrogen reduction method. No initial gas compositions were reported by the authors, only calculated $P\left(\mathrm{~S}_{2}\right)$ and $P\left(\mathrm{O}_{2}\right)$. The results are presented in Fig. 8.

Kameda and Yazawa ${ }^{[32]}$ equilibrated $\mathrm{Cu}-\mathrm{Fe}-\mathrm{O}-\mathrm{S}$ liquid with $\mathrm{CO}-\mathrm{CO}_{2}-\mathrm{SO}_{2}$ gas mixtures at 1150 to $1225{ }^{\circ} \mathrm{C}$ in alumina crucibles. The copper, iron and sulfur contents were determined analytically and the oxygen content was measured by the hydrogen reduction method. Even though ten different $\mathrm{CO} / \mathrm{CO}_{2} / \mathrm{SO}_{2}$ ratios were used, only the results for one gas composition were reported and used in the present study to calculate equilibrium $P\left(\mathrm{O}_{2}\right)$ and $P\left(\mathrm{~S}_{2}\right)$. The copperfree point is plotted in Fig. 8 .

Stofko et al. ${ }^{[33]}$ studied Fe-S-O melts in equilibrium with $\mathrm{N}_{2}-\mathrm{S}_{2}-\mathrm{SO}_{2}$ gas at $1200{ }^{\circ} \mathrm{C}$ in alumina crucibles. The quenched samples were analyzed for the iron content by titration with $\mathrm{KMnO}_{4}$, for sulfur by precipitation as $\mathrm{BaSO}_{4}$, and for oxygen by the hydrogen reduction method. No initial gas compositions were reported by the authors, instead, the calculated $P\left(\mathrm{~S}_{2}\right)$ and $P\left(\mathrm{O}_{2}\right)$ were given. The data are plotted in Fig. 8.

Mintsis et al. ${ }^{[34]}$ equilibrated $\mathrm{Fe}-\mathrm{O}-\mathrm{S}$ melts and $\mathrm{CO}-\mathrm{CO}_{2}-$ $\mathrm{SO}_{2}$ gas mixtures at 1200 and $1300{ }^{\circ} \mathrm{C}$. The iron and sulfur contents in the quenched samples were obtained by 


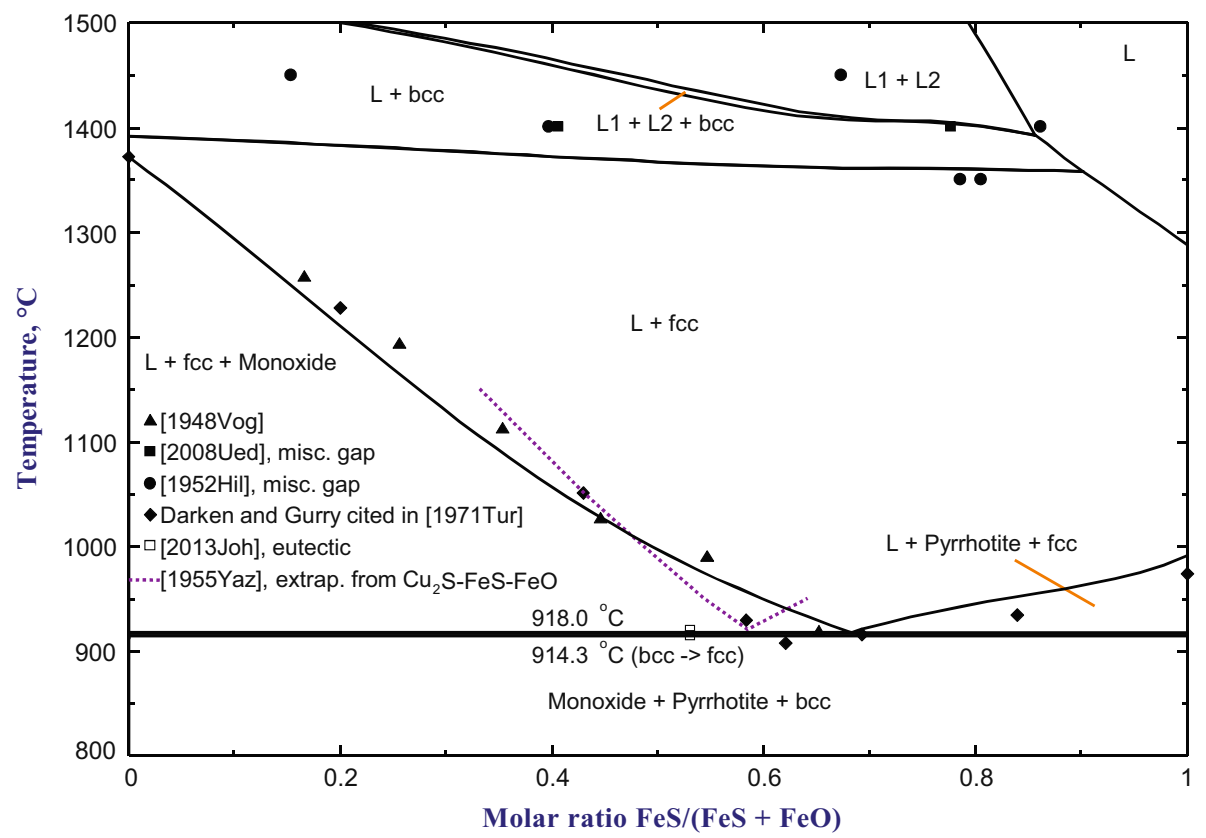

Fig. 7 Projection of the Fe-S-O phase diagram in equilibrium with iron on the FeS-FeO section through the Fe corner. Experimental points from Ref $12,21,22,27$, and 28

chemical analysis. The oxygen content was determined by difference in some samples and by an unspecified analytical method in controlled samples. The $\mathrm{CO} / \mathrm{CO}_{2} / \mathrm{SO}_{2}$ ratios were reported and used in the present study to calculate $P\left(\mathrm{O}_{2}\right)$ and $P\left(\mathrm{~S}_{2}\right)$. The results for $1200{ }^{\circ} \mathrm{C}$ are presented in Fig. 8 .

Nagamori and Yazawa ${ }^{[36]}$ equilibrated $\mathrm{Fe}-\mathrm{O}-\mathrm{S}$ melts with $\mathrm{CO}-\mathrm{CO}_{2}-\mathrm{SO}_{2}$ gas mixtures at $1200{ }^{\circ} \mathrm{C}$ in alumina crucibles. The molten samples were quenched and analyzed for oxygen, sulfur and iron. Sulfur and iron were determined gravimetrically: sulfur as $\mathrm{BaSO}_{4}$ and iron as $\mathrm{Fe}_{2} \mathrm{O}_{3}$. Oxygen was analyzed by the hydrogen reduction method. The analytical results and compositions of ingoing $\mathrm{CO}-\mathrm{CO}_{2}-\mathrm{SO}_{2}$ gas were reported. The data are given in Fig. 8.

Fonseca et al. ${ }^{[38]}$ equilibrated $\mathrm{Fe}-\mathrm{O}-\mathrm{S}$ melts with $\mathrm{CO}$ $\mathrm{CO}_{2}-\mathrm{SO}_{2}$ gas mixtures at 1200 to $1400{ }^{\circ} \mathrm{C}$ in silica crucibles. Electron microprobe analysis (EMPA) was used to measure the contents of all elements, including oxygen, in the quenched samples. The $\mathrm{CO} / \mathrm{CO}_{2} / \mathrm{SO}_{2}$ ratios were reported. The results for $1200{ }^{\circ} \mathrm{C}$ are presented in Fig. 8 .

Blatov et al. ${ }^{[35]}$ and Rose and Brenan ${ }^{[37]}$ equilibrated $\mathrm{Fe}-$ $\mathrm{O}-\mathrm{S}$ melts with $\mathrm{CO}-\mathrm{CO}_{2}-\mathrm{SO}_{2}$ gas mixtures at $1300{ }^{\circ} \mathrm{C}$. The crucible material and analytical methods were not reported in the former paper. In the latter work, San Carlos olivine mega crystal was used as a crucible and the samples were analyzed by EMPA, even for oxygen. The $\mathrm{CO} / \mathrm{CO}_{2} / \mathrm{SO}_{2}$ ratios were reported in both studies.

From Fig. 8 it is evident that there are some discrepancies between the results of different authors at $1200^{\circ} \mathrm{C}$. Nagamori and Kameda ${ }^{[31]}$ suggest lower sulfur contents and higher oxygen contents than Dewing and Richardson, ${ }^{[30]}$ Kameda and Yazawa ${ }^{[32]}$ and Stofko et al ${ }^{[33]}$ On the contrary, Fonseca et al. ${ }^{[38]}$ give higher sulfur contents and lower oxygen contents compared to the same studies. ${ }^{[30,32,33]}$ The data of Stofko et al. ${ }^{[33]}$ are rather scattered, so that the dependence on $P\left(\mathrm{~S}_{2}\right)$ is mostly within the experimental scatter, while the results of Mintsis et al. ${ }^{[34]}$ suggest that the solubility of sulfur is essentially independent of $P\left(\mathrm{~S}_{2}\right)$. The experimental data at higher temperatures $^{[34,35,37,38]}$ are even more scattered. The scatter is probably due to difficulties in attaining equilibrium between the liquid and gas phases when two partial pressures are fixed, especially at high $P\left(\mathrm{~S}_{2}\right)$.

The experimental results for the oxygen partial pressure over liquid saturated with solid iron ${ }^{[12,24,26,27]}$ are summarized in Fig. 9. These data are much more reliable and consistent.

\subsection{Solubility of Oxygen and Sulfur in Liquid Iron}

The solubility of oxygen and sulfur in metallic liquid was measured by Hilty and Crafts, ${ }^{[21]}$ Hayashi and Uno, ${ }^{[39]}$ Schenck and Hinze. ${ }^{[40]}$

Hilty and Crafts ${ }^{[21]}$ studied the equilibrium between Ferich liquid (liquid iron, L1) and FeO-rich liquid (slag, L2) in the Fe-S-O system using a rotating furnace at 1450 to $1650{ }^{\circ} \mathrm{C}$. Samples were melted in magnesia crucibles under an $\mathrm{Ar}$ atmosphere. Slag was contaminated with $\mathrm{MgO}$ from the crucible material (up to $2.5 \mathrm{wt} . \%$ ) and by $\mathrm{SiO}_{2}$ from the thermocouple protection tube (up to $4 \mathrm{wt} . \%$ ), though this is much less than the equilibrium solubility of $\mathrm{MgO}$ and $\mathrm{SiO}_{2}$ in slag under the conditions of the experiments. Samples of liquid iron were analyzed: oxygen was determined by a variant of the vacuum-fusion method and sulfur was measured gravimetrically. The experimental results are plotted in Fig. 10.

Hayashi and Uno ${ }^{[39]}$ equilibrated liquid iron with $\mathrm{H}_{2} \mathrm{~S}$ $\mathrm{H}_{2} \mathrm{O}-\mathrm{H}_{2}-\mathrm{Ar}$ mixtures at 1500 to $1600{ }^{\circ} \mathrm{C}$ in alumina crucibles. Oxygen and sulfur were analyzed by the vacuum 

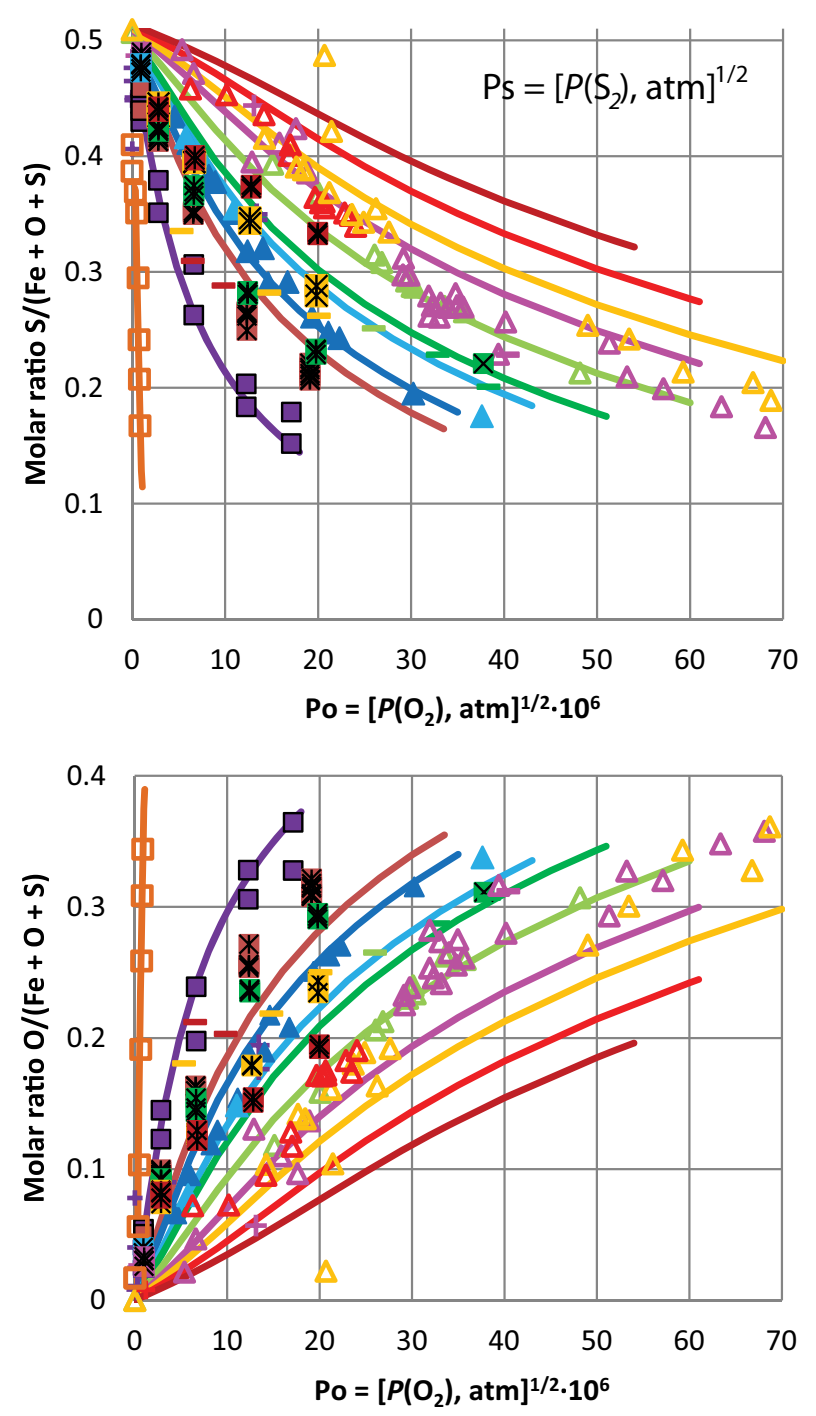

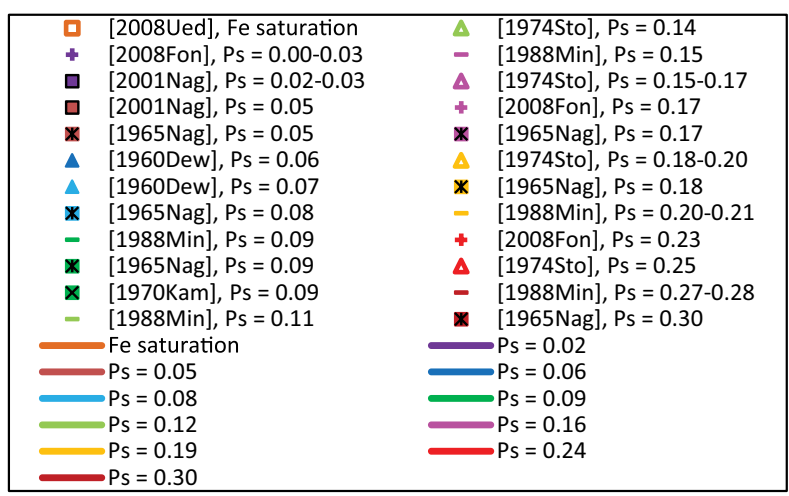

Fig. 8 Solubility of oxygen and sulfur in Fe-O-S oxysulfide melt at $1200{ }^{\circ} \mathrm{C}$

fusion method. The obtained alloy compositions are shown in Fig. 10. The equilibrium $P\left(\mathrm{O}_{2}\right)$ and $P\left(\mathrm{~S}_{2}\right)$ were calculated from the experimental gas compositions. The activity coefficient of oxygen defined as

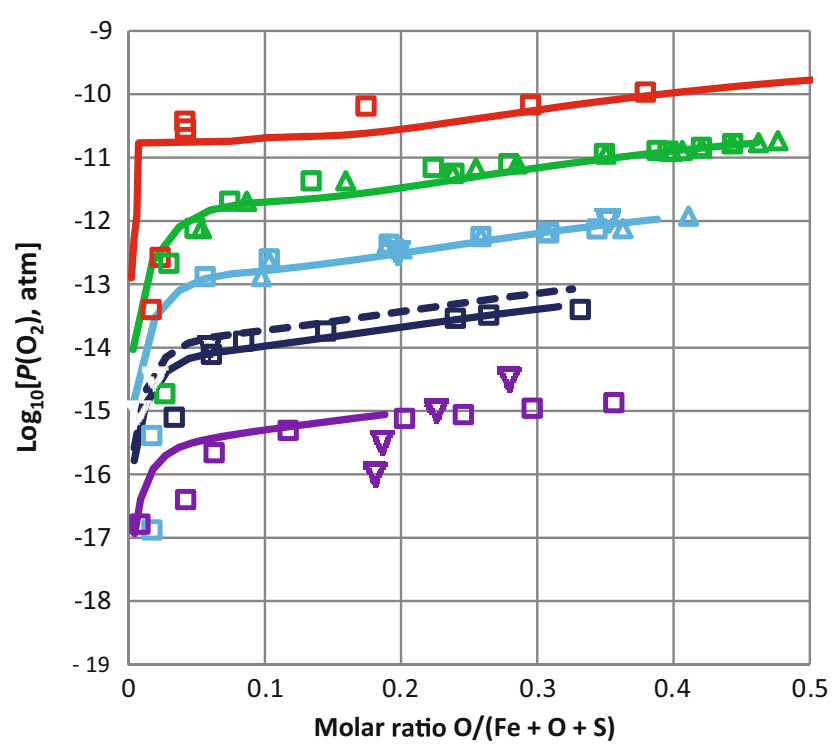

\begin{tabular}{|c|c|c|c|}
\hline & Present study, $1000^{\circ} \mathrm{C}$ & & Present study, $1100^{\circ} \mathrm{C}$ \\
\hline - & Present study, $1120^{\circ} \mathrm{C}$ & & Present study, $1200^{\circ} \mathrm{C}$ \\
\hline & Present study, $1300^{\circ} \mathrm{C}$ & & Present study, $1400^{\circ} \mathrm{C}$ \\
\hline ם & [2008Ued], $1400{ }^{\circ} \mathrm{C}$ & 口 & [2008Ued], $1300^{\circ} \mathrm{C}$ \\
\hline 口 & {$\left[2008\right.$ Ued], $1200^{\circ} \mathrm{C}$} & $\mathbf{\square}$ & [2008Ued], $1100^{\circ} \mathrm{C}$ \\
\hline ם & [2008Ued], $1000^{\circ} \mathrm{C}$ & $\nabla$ & [1959Bog], $1120^{\circ} \mathrm{C}$ \\
\hline$\Delta$ & [1997Tak], $1200{ }^{\circ} \mathrm{C}$ & $\Delta$ & [1997Tak], $1300^{\circ} \mathrm{C}$ \\
\hline$\nabla$ & [2013Joh], $1000{ }^{\circ} \mathrm{C}$ & $\nabla$ & [2013Joh], $1200{ }^{\circ} \mathrm{C}$ \\
\hline
\end{tabular}

Fig. 9 Partial pressure of oxygen for oxysulfide liquid in equilibrium with iron in the Fe-O-S system: experimental points $^{[12,24,26,27]}$ and calculated lines. The kink and horizontal part of the calculated line at $1400{ }^{\circ} \mathrm{C}$ reflect the presence of the miscibility gap

$\ln \gamma_{\mathrm{O}}=0.5 \ln P\left(\mathrm{O}_{2}\right)-\ln X_{\mathrm{O}}$

is plotted in Fig. 11. The activity coefficient of sulfur was calculated in a similar way:

$\ln \gamma_{\mathrm{S}}=0.5 \ln P\left(\mathrm{~S}_{2}\right)-\ln X_{\mathrm{S}}$

The results are shown in Fig. 12.

Schenck and Hinze ${ }^{[40]}$ equilibrated liquid iron with $\mathrm{CO} /$ $\mathrm{CO}_{2}$ gas of known composition in alumina crucibles at 1600 and $1650{ }^{\circ} \mathrm{C}$. The quenched samples were analyzed for oxygen content by gas chromatography. No analysis for S after equilibration was reported, it was assumed that the initial S content from FeS did not change. The experiments were first made using sulfur-free samples, and then the effect of sulfur on the oxygen content was measured by addition of known amounts of FeS. The activity coefficient of oxygen in the liquid phase, $f_{\mathrm{O}}$, was defined using weight rather than mole fractions as it is normally done in the technical literature ${ }^{[41]}$ :

$$
\begin{aligned}
\mu_{\mathrm{O}}= & 0.5 \mu_{\mathrm{O}_{2}}^{+}(T)+R T \ln \left(f_{\mathrm{O}} W_{\mathrm{O}}\right)=0.5\left[\mu_{\mathrm{O}_{2}}^{+}(T)\right. \\
& \left.+R T \ln P\left(\mathrm{O}_{2}\right)\right]
\end{aligned}
$$




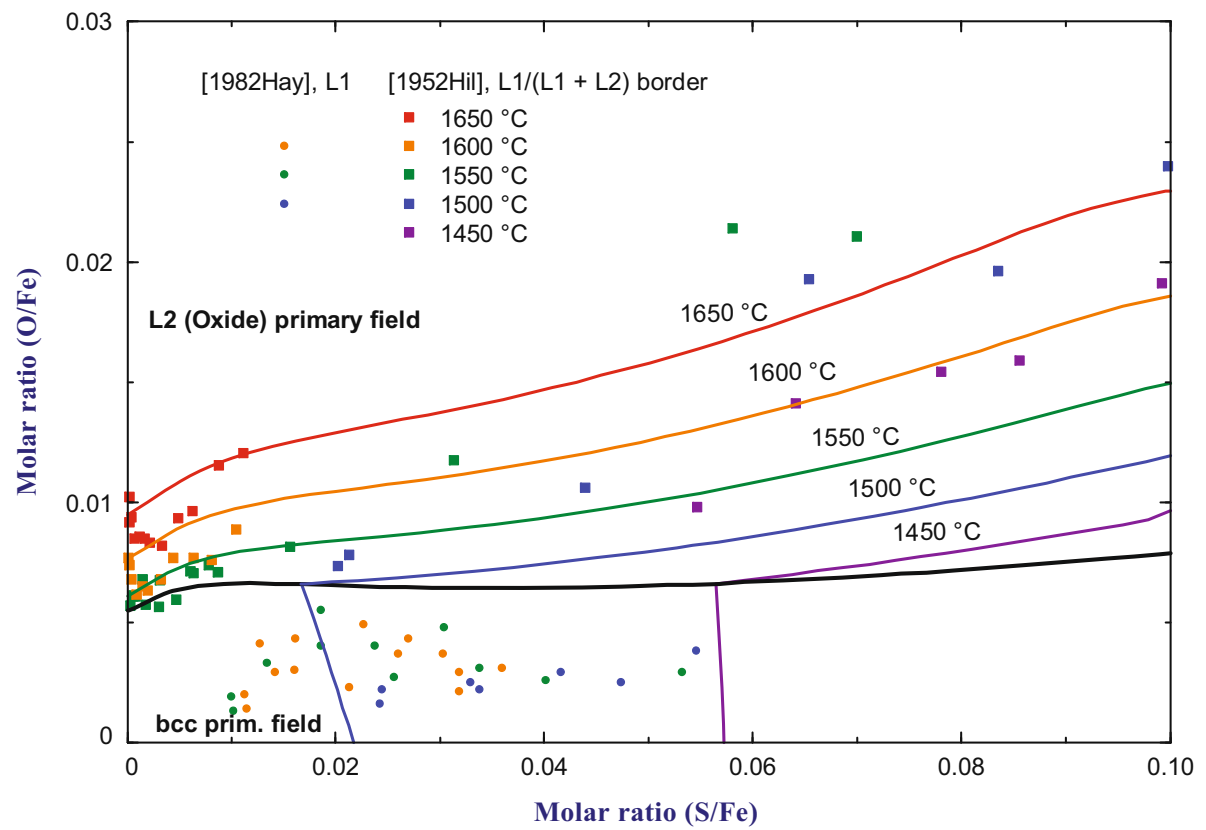

Fig. 10 Liquidus projection of the Fe-S-O system near the Fe corner. Experimental points ${ }^{[21,39]}$ and calculated lines

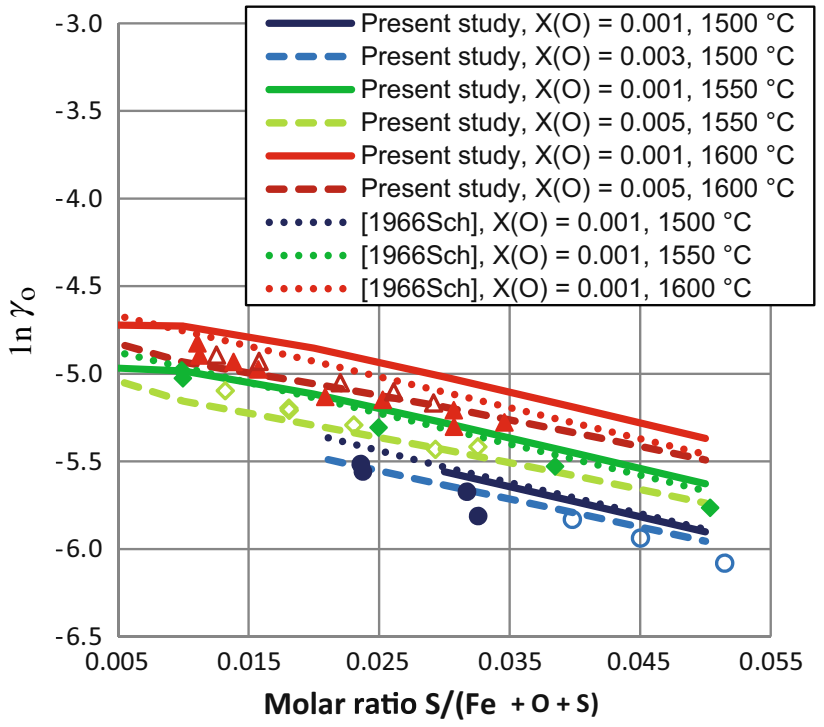

Fig. 11 Effect of sulfur on the activity coefficient of oxygen in Fe-O-S metallic liquid: experimental points ${ }^{[39]}$ and calculated lines. The amounts of oxygen for the experimental points are approximately the same as for the calculated lines of the same color; the solid and open points correspond to the solid and dashed lines, respectively. The dotted lines were calculated using parameters of Eq 14 obtained by Schenck and Hinze ${ }^{[40]}$

where $\mu_{\mathrm{O}_{2}}^{+}$is the Gibbs energy of ideal $\mathrm{O}_{2}$ gas at 1 atm, $W_{\mathrm{O}}$ is the weight fraction of oxygen and $P\left(\mathrm{O}_{2}\right)$ is the equilibrium oxygen partial pressure in atm. The composition dependence of the activity coefficient was represented by the following equation

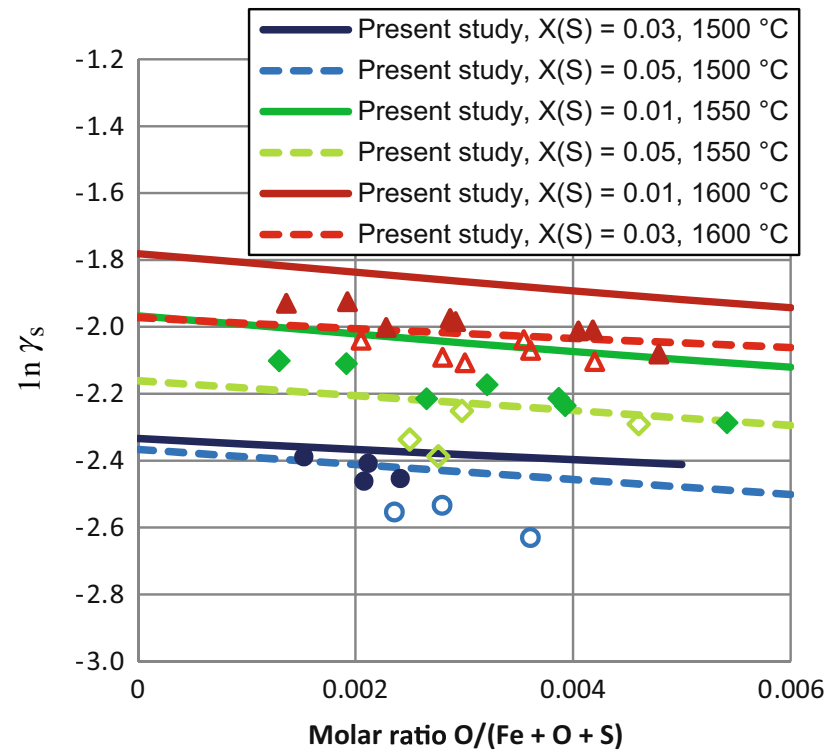

Fig. 12 Effect of oxygen on the activity coefficient of sulfur in Fe-O-S metallic liquid: experimental points ${ }^{[39]}$ and calculated lines. The amounts of sulfur for the experimental points are approximately the same as for the calculated lines of the same color; the solid and open points correspond to the solid and dashed lines, respectively

$$
\begin{aligned}
\log _{10}\left(f_{\mathrm{O}}\right)= & \log _{10}\left(f_{\mathrm{O}}^{\circ}(T)\right)+e_{\mathrm{O}}^{\mathrm{O}}(T) \cdot \text { wt. } \% \mathrm{O} \\
& +e_{\mathrm{O}}^{\mathrm{S}}(T) \cdot \text { wt. } \% \mathrm{~S}
\end{aligned}
$$

and the first-order interaction coefficient $e_{\mathrm{O}}^{\mathrm{S}}$ was obtained. This value was adopted by the Steelmaking data sourcebook. ${ }^{[41]}$ The dashed lines in Fig. 11 were calculated using 


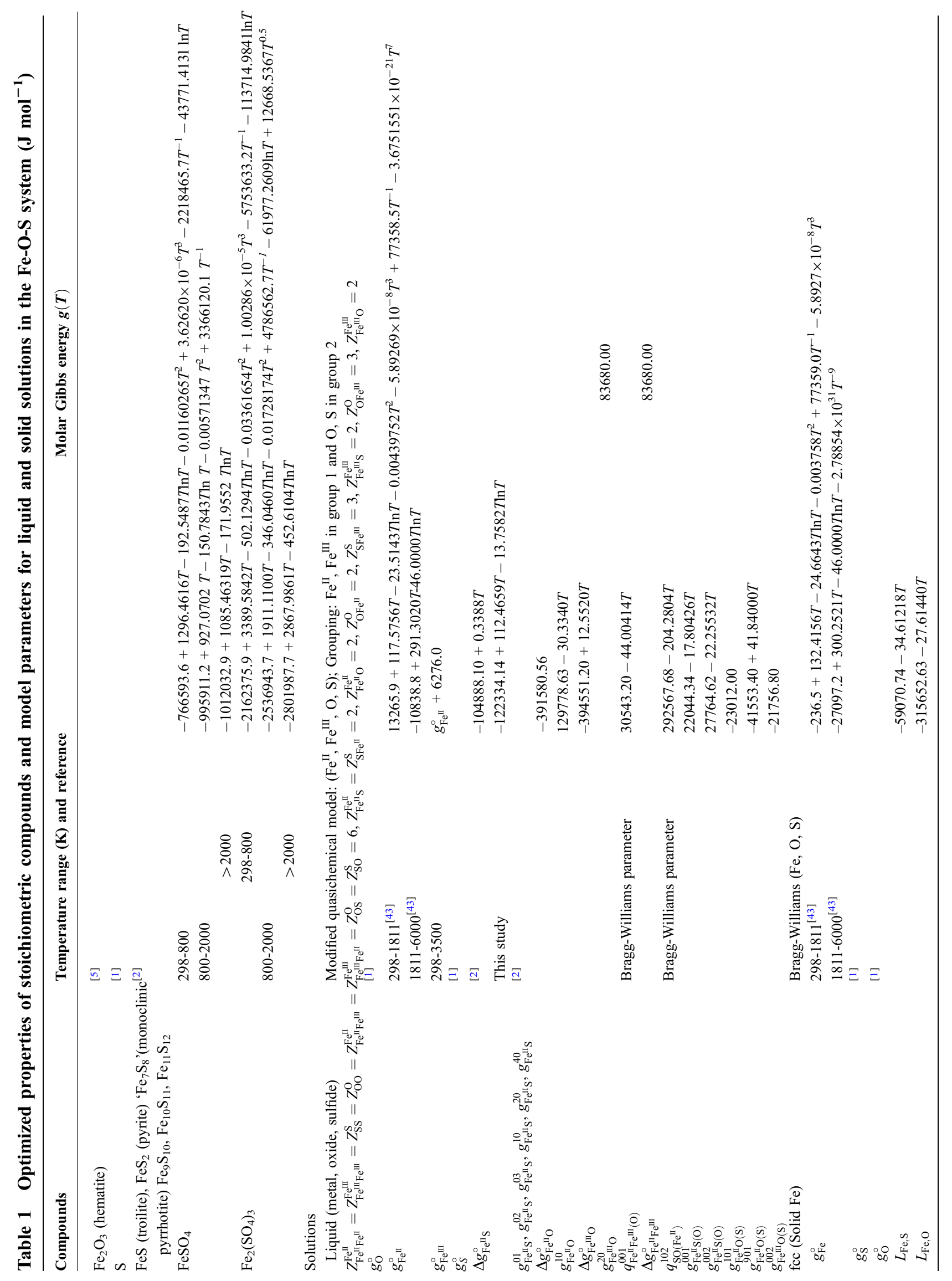




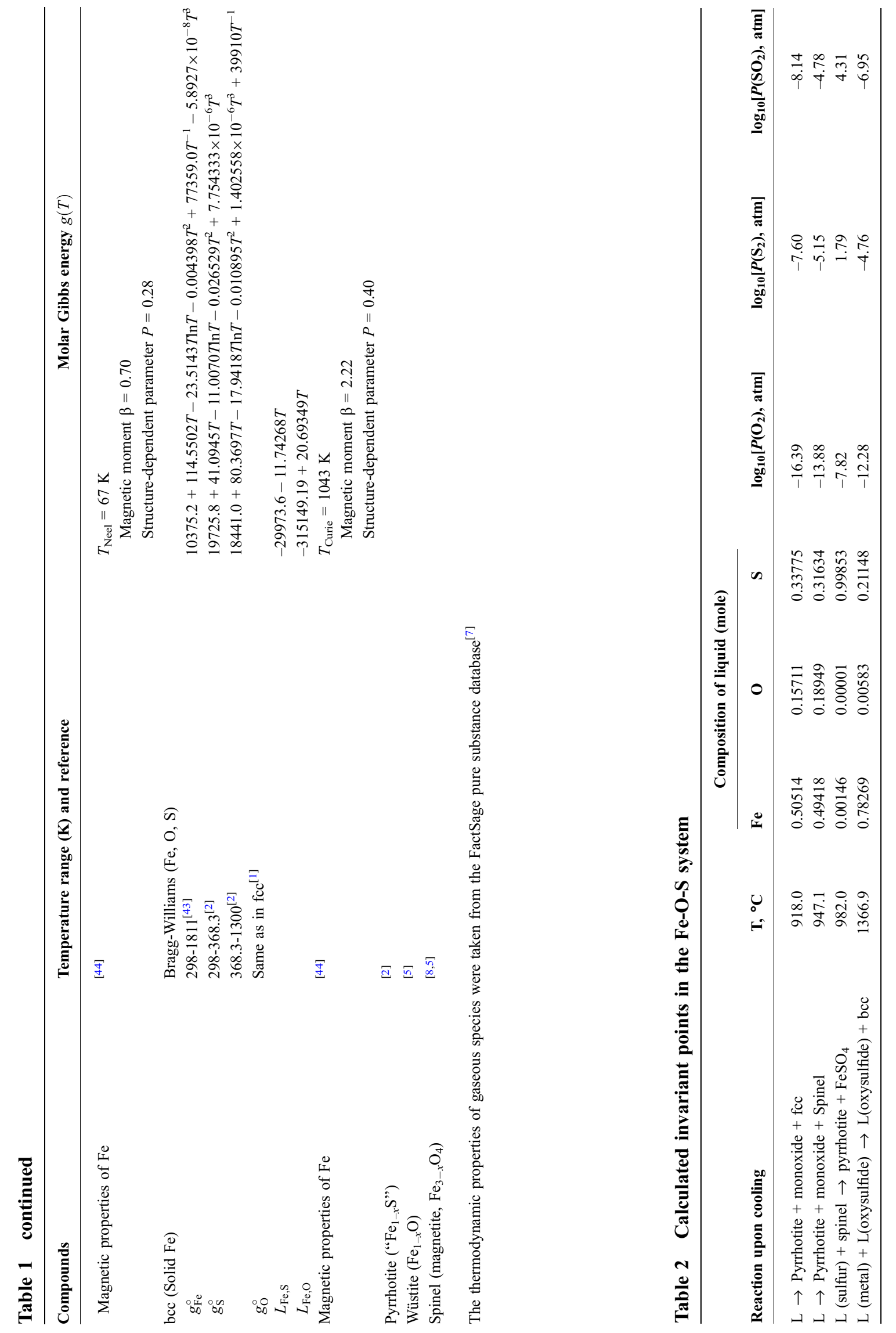


the parameters of $\mathrm{Eq} 14$ from the Steelmaking data sourcebook, ${ }^{[41]}$ assuming that $e_{\mathrm{O}}^{\mathrm{S}}$ is independent of temperature.

\subsection{Optimization}

The database for the Fe-S system ${ }^{[2]}$ was combined with the model parameters for the $\mathrm{Fe}-\mathrm{O}$ system $^{[5]}$ to predict the thermodynamic properties and phase equilibria in the $\mathrm{Fe}-\mathrm{O}$ $\mathrm{S}$ system. The thermodynamic properties of stoichiometric $\mathrm{FeSO}_{4}$ and $\mathrm{Fe}_{2}\left(\mathrm{SO}_{4}\right)_{3}$ were taken from the NIST-JANAF thermochemical tables. ${ }^{[42]}$

The phase relations in the Fe-O-S system predicted using only binary parameters for the liquid phase were qualitatively correct, but the agreement with the experimental data was not satisfactory quantitatively. Ternary parameters $g_{\mathrm{Fe}}^{001} \mathrm{II} \mathrm{S}(\mathrm{O})$ and $g_{\mathrm{Fe}^{\mathrm{II}} \mathrm{S}(\mathrm{O})}^{002}$ were introduced to raise the monoxide liquidus and the eutectic temperature shown in Fig. 7. One more ternary parameter, $g_{\mathrm{Fe}^{1 \mathrm{II}} \mathrm{O}(\mathrm{S})}$, and a Bragg-Williams parameter, $q_{\mathrm{SO}(\mathrm{Fe}}^{102}$, were required to suppress the low temperature immiscibility between liquid $\mathrm{FeS}_{1-x}$ and $\mathrm{FeO}$ and to increase the iron content in iron-saturated liquid (see Fig. 6). Another ternary parameter, $g_{\mathrm{Fe}^{\mathrm{III}} \mathrm{O}(\mathrm{S})}^{02}$, was added to shift the phase boundary $\mathrm{L} /(\mathrm{L}+$ Spinel + Gas $)$ in Fig. 6(b) and (d) to higher $\mathrm{S}$ and $\mathrm{O}$ contents.

The binary parameter $\Delta g_{\mathrm{Fe}^{\mathrm{II}} \mathrm{S}}^{\circ}$ was adjusted to raise $\gamma_{\mathrm{S}}$ in iron-rich Fe-S liquid at 1500 to $1600{ }^{\circ} \mathrm{C}$ in order to improve the description of the data of Hayashi and Uno ${ }^{[39]}$ shown in Fig. 12. This did not impair the overall description of the experimental data in the Fe-S system. An additional parameter, $g_{\mathrm{Fe}^{\mathrm{II}} \mathrm{O}(\mathrm{S})}^{90}$, was used to raise $\gamma_{\mathrm{O}}$ and $\gamma_{\mathrm{S}}$ in liquid iron (see Fig. 11, 12). However, the solubility of oxygen in liquid iron equilibrated with slag falls when $\gamma_{0}$ increases, which made the description of the data of Hilty and Crafts $^{[21]}$ shown in Fig. 10 less accurate. A better fit of the data of Hayashi and Uno ${ }^{[39]}$ and of Schenck and Hinze ${ }^{[40]}$ would result in a large disagreement with the solubility data of Hilty and Crafts, ${ }^{[21]}$ and also with the miscibility gap in Fig. 6(f,g) as reported by Hilty and Crafts ${ }^{[21]}$ and Ueda et al. ${ }^{[27]}$ And vice versa, if the miscibility gap between liquid iron and liquid oxysulfide were described more accurately, the activity coefficient of oxygen in Fig. 11 would fall dramatically. To resolve this contradiction, more experimental studies are required in the liquid iron region of the Fe-O-S system. In the present study, the model parameters were optimized to attain a reasonable compromise between the data on the activity coefficients of oxygen and sulfur in liquid iron ${ }^{[39,40]}$ and the data on phase equilibria with oxysulfide liquid. ${ }^{[21,27]}$

The resulting description of the available experimental data is shown by the calculated lines in Fig. 3-12. In most cases the agreement is within the experimental error limits. However, the calculated miscibility gap L1 + L2 shown in Fig. 6(e, f) and 16 expands less rapidly with increasing temperature than suggested by the data of Hilty and Crafts $^{[21]}$ and Ueda et al. ${ }^{[27]}$ The experimental $\mathrm{L} 1+\mathrm{L} 2+$ bcc triangles at 1400 and $1450{ }^{\circ} \mathrm{C}$ are close to the calculated ones at 1470 and $1505{ }^{\circ} \mathrm{C}$, respectively.

From the data on the solubility of oxygen and sulfur at fixed $P\left(\mathrm{O}_{2}\right)$ and $P\left(\mathrm{~S}_{2}\right)$ summarized in Fig. 8, oxygen and sulfur isobars over the matte region can be calculated. In particular, these isobars at 1200 and $1300{ }^{\circ} \mathrm{C}$ are presented in Fig. 6(d, e).

The thermodynamic properties of all stoichiometric compounds and the values of the optimized model parameters are given in Table 1 . The optimized parameters are strongly correlated and, therefore, are given in Table 1 with relatively large numbers of significant digits. The calculated invariant points are listed in Table 2 .

\section{Conclusions}

A critical assessment and thermodynamic modeling have been performed for the Fe-O-S system over the whole composition range. A model for the liquid phase has been developed within the framework of the quasichemical formalism. This model describes simultaneously metallic liquid, sulfide liquid (matte) and oxide liquid (slag). For the $\mathrm{Fe}-\mathrm{O}$ system, the model reflects the existence of two ranges of maximum SRO at approximately $\mathrm{FeO}$ and $\mathrm{Fe}_{2} \mathrm{O}_{3}$ compositions. Parameters of thermodynamic models for the liquid and solid phases have been optimized to provide the best description of all available thermodynamic and phase equilibrium data. The obtained self-consistent set of model parameters can be used to calculate the solubility of oxygen and sulfur in liquid and solid iron. The stability range of oxysulfide liquid can also be calculated at different temperatures along with the equilibrium oxygen and sulfur partial pressures at each composition.

The model parameters obtained in the present study are being used for development of a thermodynamic database for simulation of copper smelting and converting. In particular, the model and optimized properties of the liquid phase are essential for description of the solubility of oxygen in matte. The present study completes the optimization of all binary and ternary subsystems of the $\mathrm{Cu}-\mathrm{Fe}-$ $\mathrm{O}-\mathrm{S}$ quaternary system. The experimental data available for the $\mathrm{Cu}-\mathrm{Fe}-\mathrm{O}-\mathrm{S}$ system were compared with the predictions from the combined database. Even though the agreement was fair, it was found that the $\mathrm{Cu}-\mathrm{Fe}-\mathrm{S}^{[2-4]}$ optimization needs some improvement. Just a few additional model parameters that reflect interactions, which are present only in the quaternary system, may also be added to improve the description. The optimization of the $\mathrm{Cu}-\mathrm{Fe}-\mathrm{O}-\mathrm{S}$ quaternary system will be reported elsewhere.

\section{References}

1. D. Shishin and S.A. Decterov, Critical Assessment and Thermodynamic Modeling of $\mathrm{Cu}-\mathrm{O}$ and $\mathrm{Cu}-\mathrm{O}-\mathrm{S}$ Systems, CALPHAD, 2012, 38, p 59-70

2. P. Waldner and A.D. Pelton, Thermodynamic Modeling of the Fe-S System, J. Phase Equilib. Diff., 2005, 26, p 23-28

3. P. Waldner, Thermodynamic Modeling of the Cu-S System, Internal Report, Ecole Polytechnioque de Montreal, Montreal, QC, 2005 
4. P. Waldner and A.D. Pelton, Thermodynamic Modeling of the $\mathrm{Cu}-\mathrm{S}$ System, Internal Report, Ecole Polytechnioque de Montreal, Montreal, QC, 2006

5. T. Hidayat, D. Shishin, E. Jak, and S. Decterov, Thermodynamic Reevaluation of the Fe-O System, Calphad, 2015, 48, p 131-144

6. D. Shishin, T. Hidayat, E. Jak, and S. Decterov, Critical Assessment and Thermodynamic Modeling of Cu-Fe-O System, CALPHAD, 2013, 41, p 160-179

7. C.W. Bale, E. Belisle, P. Chartrand, S.A. Decterov, G. Eriksson, K. Hack, I.-H. Jung, Y.-B. Kang, J. Melancon, A.D. Pelton, C. Robelin, and S. Petersen, FactSage Thermochemical Software and Databases-Recent Developments, CALPHAD, 2009, 33(2), p 295-311

8. S.A. Decterov, E. Jak, P.C. Hayes, and A.D. Pelton, Experimental Study and Thermodynamic Optimization of the Fe-Zn-O System, Metall. Mater. Trans. B, 2001, 32B(4), p 643-657

9. A.D. Pelton, S.A. Decterov, G. Eriksson, C. Robelin, and Y. Dessureault, The Modified Quasichemical Model. I-Binary Solutions, Metall. Mater. Trans. B, 2000, 31B(4), p 651-659

10. A.D. Pelton and P. Chartrand, The Modified Quasichemical Model. II-Multicomponent Solutions, Metall. Mater. Trans. $A, 2001,32 \mathrm{~A}(6), \mathrm{p} 1355-1360$

11. R. Vogel and W. Fulling: The System Iron-Iron Sulfide (FeS)Wustite (FeO), Festskr. J. Arvid Hedvall, 1948, p 597-610

12. H. Johto, H.M. Henao, E. Jak, and P. Taskinen, Experimental Study on the Phase Diagram of the Fe-O-S System, Metall. Mater. Trans. B, 2013, 44(6), p 1364-1370

13. D. Shishin, "Development of a thermodynamic database for copper smelting and converting", Ph. D. thesis, Ecole Polytechnique of Montreal, 2013

14. J.M. Skeaff and A.W. Espelund, Electromotive Force Method for the Determination of Sulfate-Oxide Equilibria Results for the Magnesium, Manganese, Iron, Nickel, Copper and Zinc Systems, Can. Metall. Q., 1973, 12(4), p 445-454

15. K.C. Hsieh and Y.A. Chang, A Solid-State Emf Study of Ternary Nickel-Sulfur-Oxygen, Iron-Sulfur-Oxygen, and Quaternary Iron-Nickel-Sulfur-Oxygen, Metall. Trans. B, 1986, 17B(1), p 133-146

16. T. Rosenqvist and A. Hofseth, Phase Relations and Thermodynamics of the Copper-Iron-Sulfur-Oxygen System at 700$1000{ }^{\circ} \mathrm{C}$, Scand. J. Metall., 1980, 9(3), p 129-138

17. O.A. Musbah and Y.A. Chang, A Solid-State EMF Study of the Fe-S-O and Co-S-O Ternary Systems, Oxid. Met., 1988, 30(5-6), p 329-342

18. S.C. Schaefer, Electrochemical Determination of Gibbs Energies of Formation of Manganese Sulfide and Iron Sulfide(Fe0.9S), RI, 8486, Albany Res. Cent. Bur. Mines, Albany, OR, 1980

19. A.W. Espelund and H. Jynge, The Zinc-Iron-Sulfur-Oxygen System Equilibriums Between Sphalerite or Wurtzite, Pyrrhotite, Spinel, Zinc Oxide and a Gas Phase, Scand. J. Metall., 1977, 6(6), p 256-262

20. T. Rosenqvist and P.H. Hynne, The Reaction Between Iron Sulfide and Sulfur Dioxide, Tidsskr. Kjemi. Bergves. Metall., 1953, 13, p 196-200

21. D.C. Hilty and W. Crafts, Liquidus Surface of the Iron-SulfurOxygen System, J. Metals, 1952, 194, p 1307-1312

22. E.T. Turkdogan, G.J.W. Kor, L.S. Darken, and R.W. Gurry, Sulfides and Oxides in Iron-Manganese Alloys. I. Phase Relations in Iron-Manganese-Sulfur-Oxygen System, Metall. Trans., 1971, 2(6), p 1561-1570

23. T. Rosenqvist and T. Hartvig, The Thermodynamics of Fe-Cu Mattes, and Their Equilibrium with Magnetite, Norges TekNaturvitenskapelige Forskiningsrud Met. Kom. Meddel, 1958, 12, p 21-52
24. S. Bog and T. Rosenqvist, A Thermodynamic Study of Iron Sulphide-Iron Oxide Melts. Nat. Phys. Lab. Symp. No. 9, NPL, Teddington, 1959

25. A.J. Naldrett, A Portion of the System Fe-S-O Between 900 and $1080{ }^{\circ} \mathrm{C}$ and Its Application to Sulfide Ore Magmas, $J$. Petrol., 1969, 10(2), p 171-201

26. Y. Takeda, Oxygen potential measurement of iron silicate slagcopper-matte system. Proceedings of International Conference Molten Slags, Fluxes Salts '97, 5th. Iron and Steel Society, Warrendale, PA, 1997

27. S. Ueda, K. Yamaguchi, and Y. Takeda, Phase Equilibrium and Activities of Fe-S-O Melts, Mater. Trans., 2008, 49(3), p 572578

28. A. Yazawa and M. Kameda, Fundamental Studies on Copper Smelting. III. Partial Liquidus Diagram for $\mathrm{Cu}_{2} \mathrm{~S}-\mathrm{FeS}-\mathrm{FeO}$ System, Technol. Rep. Tohoku Univ., 1955, 19(2), p 239-250

29. Y.S. Lee, S.M. Jung, and D.J. Min, Thermodynamic Study on Phase Equilibria in the Liquid Fe-S-O System, Steel Res., 2002, 73(11), p 461-466

30. E.W. Dewing and F.D. Richardson, Thermodynamics of Mixtures of Ferrous Sulphide and Oxide, J. Iron Steel Inst., 1960, 194, p 446-450

31. M. Nagamori and M. Kameda, Equilibriums Between the Fe$\mathrm{S}-\mathrm{O}$ System Melts and $\mathrm{CO}-\mathrm{CO}_{2}-\mathrm{SO}_{2}$ Gas Mixtures at $1200^{\circ}$, Trans. Inst. Metals (Jpn.), 1965, 6, p 21-30

32. M. Kameda and A. Yazawa: Effects of Partial Pressures of Oxygen and Sulfur on the Oxygen Content in Copper Matte. Studies in Met. (Commemoration for Prof. Matoba), Tohoku University, 1970

33. M. Stofko, J. Schmiedl, and T. Rosenqvist, Thermodynamics of Iron-Sulfur-Oxygen Melts at $1200{ }^{\circ} \mathrm{C}$, Scand. J. Metall., 1974, 3(3), p 113-118

34. V.P. Mintsis, A.G. Ryabko, L.S. Tsemekhman, G.P. Grodinskii, and Y.V. Fisher, Equilibrium in the Iron-Sulfur-Oxygen System, Izv. Akad. Nauk SSSR Met., 1988, 1, p 28-32

35. I.A. Blatov, B.P. Burylev, L.S. Tsemekhman, and S.L. Litvinov, Thermodynamics of the Interaction of Components of the Fe-S-O System in Equilibrium with the $\mathrm{CO}-\mathrm{CO}_{2}-\mathrm{SO}_{2}$ Gas Phase at $1300{ }^{\circ} \mathrm{C}$, Metally, 1997, 6, p 34-36

36. M. Nagamori and A. Yazawa, Thermodynamic Observations of the Molten FeS-FeO System and Its Vicinity at $1473 \mathrm{~K}$, Metall. Mater. Trans. B, 2001, 32B(5), p 831-837

37. L.A. Rose and J.M. Brenan, Wetting Properties of Fe-Ni-Co$\mathrm{Cu}-\mathrm{O}-\mathrm{S}$ Melts Against Olivine: Implications for Sulfide Melt Mobility, Econ. Geol., 2001, 96(1), p 145-157

38. R.O.C. Fonseca, I.H. Campbell, H.S.C. O’Neill, and J.D. Fitzgerald, Oxygen Solubility and Speciation in Sulphide-Rich Mattes, Geochim. Cosmochim. Acta, 2008, 72(11), p 2619-2635

39. S. Hayashi and T. Uno, Activities of Sulfur and Oxygen in Liquid Iron, Tetsu to Hagane, 1982, 68(13), p 1728-1736

40. H. Schenck and H. Hinze, Equilibriums of the Iron-CarbonOxygen System in the Temperature and Concentration Range of Molten Steel and the Effect of Phosphorus, Manganese, and Sulfur, Arch. Eisenhuettenwes., 1966, 37(7), p 545-553

41. Steelmaking Data Sourcebook. Japan Society for the Promotion of Science, 19th Comm. On Steelmaking, Gordon \& Breach Science, New York, NY, 1988, 312 pp

42. M. Chase, NIST-JANAF Thermochemical Tables, 4th ed., NIST, Gaithersburg, 1998

43. A.T. Dinsdale, SGTE Data for Pure Elements, CALPHAD, 1991, 15, p 317-425

44. I. Ansara and Å. Jansson, Assesment of the Copper-Iron System, Materials Research Center, The Royal Institute of Technology, Stockholm, Sweden, 1993 